\title{
Peroxyl radical- and photo-oxidation of glucose 6- phosphate dehydrogenase generates cross-links and functional changes via oxidation of tyrosine and tryptophan residues
}

Leinisch, Fabian; Mariotti, Michele; Rykær, Martin; Lopez-Alarcon, Camilo; Hägglund, Per; Davies, Michael Jonathan

\section{Published in:}

Free Radical Biology \& Medicine

Link to article, DOI:

10.1016/j.freeradbiomed.2017.07.025

Publication date:

2017

Document Version

Peer reviewed version

Link back to DTU Orbit

Citation (APA):

Leinisch, F., Mariotti, M., Rykær, M., Lopez-Alarcon, C., Hägglund, P., \& Davies, M. J. (2017). Peroxyl radicaland photo-oxidation of glucose 6 - phosphate dehydrogenase generates cross-links and functional changes via oxidation of tyrosine and tryptophan residues. Free Radical Biology \& Medicine, 112, 240-252.

https://doi.org/10.1016/j.freeradbiomed.2017.07.025

\section{General rights}

Copyright and moral rights for the publications made accessible in the public portal are retained by the authors and/or other copyright owners and it is a condition of accessing publications that users recognise and abide by the legal requirements associated with these rights.

- Users may download and print one copy of any publication from the public portal for the purpose of private study or research.

- You may not further distribute the material or use it for any profit-making activity or commercial gain

- You may freely distribute the URL identifying the publication in the public portal 
Peroxyl radical- and photo-oxidation of glucose 6-phosphate dehydrogenase generates cross-links and functional changes via oxidation of tyrosine and tryptophan residues

Fabian Leinisch ${ }^{1}$, Michele Mariotti $^{2}$, Martin Rykaer $^{2}$, Camilo Lopez-Alarcon $^{3}$, Per Hägglund ${ }^{2}$ and Michael J. Davies ${ }^{1}$

${ }^{1}$ Dept. of Biomedical Sciences, Panum Institute, University of Copenhagen, Copenhagen, Denmark;

${ }^{2}$ Department of Biotechnology and Biomedicine, Technical University of Denmark, Kongens Lyngby, Denmark

${ }^{3}$ Departamento de Química Física, Facultad de Química, Pontificia Universidad Catolica de Chile, Avda. Vicuña Mackenna 4860, Santiago, Chile

Abbreviations: AAPH, 2,2'-azobis(2-amidinopropane) dihydrochloride; G6PDH, glucose-6-phosphate dehydrogenase; NFK, N-formyl kynurenine; UPLC, ultra high pressure liquid chromatography, MS, mass spectrometry, OPA, o-phthaldialdehyde ; PAGE, polyacrylamide gel electrophoresis; SDS, sodium dodecylsulfate.

* Corresponding author. E-mail address: davies@sund.ku.dk (M.J. Davies) 


\section{ABSTRACT}

Protein oxidation is a frequent event as a result of the high abundance of proteins in biological samples and the multiple processes that generate oxidants. The reactions that occur are complex and poorly understood, but can generate major structural and functional changes on proteins. Current data indicate that pathophysiological processes and multiple human diseases are associated with the accumulation of damaged proteins. In this study we investigated the mechanisms and consequences of exposure of the key metabolic enzyme glucose-6-phosphate dehydrogenase $(\mathrm{G6PDH})$ to peroxyl radicals $\left(\mathrm{ROO}^{\circ}\right)$ and singlet oxygen $\left({ }^{1} \mathrm{O}_{2}\right)$, with particular emphasis on the role of Trp and Tyr residues in protein cross-linking and fragmentation. Cross-links and high molecular mass aggregates were detected by SDSPAGE and Western blotting using specific antibodies. Amino acid analysis has provided evidence for Trp and Tyr consumption and formation of oxygenated products (diols, peroxides, $\mathrm{N}$-formylkynurenine, kynurenine) from Trp, and di-tyrosine (from Tyr). Mass spectrometric data obtained after trypsin-digestion in the presence of $\mathrm{H}_{2}{ }^{16} \mathrm{O}$ and $\mathrm{H}_{2}{ }^{18} \mathrm{O}$, has allowed the mapping of specific cross-linked residues and their locations. These data indicate that specific Tyr-Trp and di-Tyr cross-links are formed from residues that are proximal and surface-accessible, and that the extent of Trp oxidation varies markedly between sites. Limited modification at other residues is also detected. These data indicate that Trp and Tyr residues are readily modified by $\mathrm{ROO}^{\bullet}$ and ${ }^{1} \mathrm{O}_{2}$ with this giving products that impact significantly on protein structure and function. The formation of such cross-links may help rationalize the accumulation of damaged proteins in vivo.

Keywords: Protein oxidation, cross-links, glucose-6-phosphate dehydrogenase, peroxyl radicals, photo-oxidation, dityrosine, aggregation, singlet oxygen 


\section{Introduction}

Protein oxidation is a frequent event as a result of the high abundance of proteins in biological samples and the large number of endogenous (e.g. electron leakage from mitochondria, enzyme and autoxidation reactions) and exogenous (metal ions, atmospheric pollutants, high energy radiation, UV light) stimuli that can generate reactive oxidants (reviewed: [1]). These reactions are complex and poorly understood, but it is known that multiple processes are involved, and that this can give rise to major structural and functional changes on target proteins (reviewed: [2]). Evidence has been provided to support the hypothesis that such reactions, and the accumulation of damaged proteins, can play a major role in a number of human diseases (e.g. some cancers, neurodegenerative conditions, cardiovascular disease, asthma, rheumatoid arthritis [1,2]).

The mechanisms of amino acid and peptide oxidation by some one- and two-electron oxidants (e.g. $\mathrm{HO}^{\bullet}, \mathrm{ONOOH}, \mathrm{HOCl},{ }^{1} \mathrm{O}_{2}$ ) have been examined extensively [2-9]. In each case sulfur-containing amino acids (Cys, Met and cystine) are major targets, and considerable information is available as to the consequences of these reactions. In the case of Cys oxidation, cystine is a major product if the two Cys residues are appropriately positioned, and this can give rise to both intra- and inter-molecular cross-links. These cross-links are readily repaired by disulfide reductase enzymes and are often transient in biological systems [10]. Limited data is also available for cross-linking of Met residues [11,12]. Tyr and Trp residues are also major targets for each of these oxidants, and there is considerable evidence that these processes can give rise to irreversible cross-links. Thus Tyr residues can be oxidized to Tyr phenoxyl radicals that dimerize to give di-Tyr (a C-C linked dimer) and iso-di-Tyr (a C-O linked dimer) (reviewed [13]). Recent studies have also provided evidence for Trp-Trp dimers, but these are less well characterized with regard to their abundance and importance 
$[14,15]$. Other cross-linked species can also be formed (e.g. Tyr-Trp [16] and His-His [1719]). Carbon-carbon cross-links between aliphatic side-chains are also known [20]. In some cases the identity and position of the residues involved in cross-link formation have been elucidated, but in other cases only the overall effects has been examined (e.g. via the detection of dimers and higher oligomers by SDS-PAGE, detection of di-Tyr in protein hydrolysates by HPLC, or detection of di-Tyr fluorescence on intact proteins) [13]. The paucity of information on the involvement of specific residues in cross-link formation is due, at least in part, to the problems inherent in identifying dimeric peptides in enzymatic digests of oxidized proteins by mass spectrometry (MS), as these are typically of low abundance, and the number of possible permutations are large for most proteins. However the formation of non-reducible, covalently-linked, oligomers may have important biological effects, both in respect to a potential loss of function, and as a result of the accumulation of damaged crosslinked materials in cells, and subsequent adverse toxic effects, due to a decreased rate of clearance by proteasomal, lysosomal and other pathways [21-24].

Recent advances in MS methods, and particularly the development of high-resolution instruments and specific methods for detecting cross-linked peptides using enzymatic digestion in $\mathrm{H}_{2}{ }^{18} \mathrm{O}$ [25], have prompted us to examine the incidence, nature and structural consequences of cross-link formation on a model protein, glucose-6-phosphate dehydrogenase (G6PDH). This enzyme catalyzes the pace-making step of the pentose phosphate pathway that is responsible for much of the NADPH formation within cells. Maintenance of NADPH levels is critical to cell survival, as this is an essential co-factor for multiple cellular protective pathways against oxidative damage, including the NADPH/glutathione reductase/ GSH/glutathione peroxidase system, and the NADPH/thioredoxin reductase/thioredoxin/ peroxiredoxin system [1]. Thus inhibition, or 
loss, of G6PDH activity by oxidation [26], or cross-linking induced by hydroxynonenal [27], can compromise cell survival.

Decreased G6PDH activity is one of the most common genetic mutations [28,29], manifested clinically as hemolytic anemia, which can be triggered by ingestion of fava beans, or conditions associated with oxidative damage such as diabetes, myocardial infarction and strenuous physical exercise [29]. In people with diabetes, decreased G6PDH activity is associated with poor glycemic control [30] and an increased level of protein oxidation products $[31,32]$. Symptoms of G6PDH deficiency have been reported to include indications of protein oxidation, with cellular organelles ageing faster and containing increased levels of oxidation markers [30,33]. Oxidative damage may therefore result in a downward spiral, as enzyme deficiency or loss of activity is associated with a decreased capacity to protect against oxidative damage, and an increased extent of oxidation of G6PDH [31,32].

In the study reported here, we have investigated damage to G6PDH induced by two biologically-relevant oxidant systems: singlet oxygen $\left({ }^{1} \mathrm{O}_{2}\right.$; molecular oxygen in the excited ${ }^{1} \Delta_{\mathrm{g}}$ state), generated by use of the photosensitizer Rose Bengal in the presence of visible light and $\mathrm{O}_{2}$, and peroxyl radical $\left(\mathrm{ROO}^{\circ}\right)$ generated by the thermolabile azo compound 2,2'azobis(2-amidinopropane) dihydrochloride (AAPH). ${ }^{1} \mathrm{O}_{2}$ is known to be generated by a wide range of biological and chemical reactions, including photochemical reactions, reactions of peroxidase enzymes, termination reactions of peroxyl radicals and the reaction of $\mathrm{H}_{2} \mathrm{O}_{2}$ with $\mathrm{HOCl}$, amongst others $[8,34] . \mathrm{ROO}^{\bullet}$ are major intermediates in many oxidation reactions that occur under normoxic conditions, as a result of the rapid (typically diffusion-controlled) reaction of $\mathrm{O}_{2}$ with carbon-centered radicals, with these being key intermediates in lipid and protein peroxidation reactions, and the decomposition of hydroperoxides $[2,35,36]$.

Understanding the mechanisms and consequences of the reaction of these species with cellular proteins, and the formation of modified proteins is therefore of considerable 
significance. Previous studies with other proteins have provided evidence for selective damage by ${ }^{1} \mathrm{O}_{2}$ and $\mathrm{ROO}^{\bullet}$, and the formation of cross-linked materials, though the exact nature of these species could not be determined [37]. We therefore hypothesized that these oxidants would give rise to extensive modification of G6PDH via oxidation at readily oxidized residues (e.g. Trp, Tyr, His, Met) and that this would give rise to structurally modified, and enzymatically-inactive protein, potentially as a result of cross-link formation.

\section{Materials and Methods}

\subsection{Materials}

Chemicals and reagents were from Sigma Aldrich (St Louis, MO). Chelex was obtained from Biorad (Hercules, CA, USA). Dityrosine and NFK were obtained from Toronto Research Chemicals (Toronto, CA), unless stated otherwise. The anti-dityrosine antibody was obtained from Japan Institute for the Control of Aging (JaICA, Haruoka, Japan), and the anti-NFK antibody was a gift from Prof. Ron Mason and Dr. Marilyn Ehrenshaft (National Institute of Environmental Health Sciences, Research Triangle Park, USA). Glucose-6-phosphate dehydrogenase (from Leuconostoc mesenteroides, $100 \mu \mathrm{M}, 10$ $\left.\mathrm{mg} \mathrm{mL} \mathrm{m}^{-1}\right)$ was dissolved in phosphate buffer (100 mM, pH 7.4) made up with Milli-Q water and treated with Chelex-100 to remove trace metal ions.

\subsection{Sensitized photo-oxidation of G6PDH}

Oxidations were carried out as described previously [38] with minor modifications. The protein solution was diluted with $\mathrm{D}_{2} \mathrm{O}(70 \% \mathrm{v} / \mathrm{v}$ final $)$ to a final concentration of $30 \mu \mathrm{M}$ $\left(3 \mathrm{mg} \mathrm{mL}^{-1}\right)$ protein and $10 \mathrm{mM}$ phosphate buffer, $\mathrm{pH}$ 7.4. Rose Bengal (10 $\mu \mathrm{M}$ final) was added and samples were illuminated using a Leica $\mathrm{P} 150$ slide projector through a 
polystyrene UV filter for $90 \mathrm{~min}$ at $4{ }^{\circ} \mathrm{C}$. Control samples were exposed for the same time in the absence of Rose Bengal, or incubated for the same period with Rose Bengal in the absence of light. The photon flux was determined as $2 \times 10^{16}$ photons s ${ }^{-1}$ using a $\mathrm{Ru}(\mathrm{BPY})_{3} \mathrm{Cl}_{2} /$ diphenylanthracene actinometer [39].

\subsection{Peroxyl radical-mediated oxidation of G6PDH}

Peroxyl radical-mediated oxidation was carried out as described previously [40] with minor modifications. Protein solutions $\left(30 \mu \mathrm{M}, 3 \mathrm{mg} \mathrm{mL}^{-1}\right.$ protein, $100 \mathrm{mM}$ phosphate buffer final concentrations) were incubated with 2,2'-azobis(2-amidinopropane) dihydrochloride (AAPH, $10 \mathrm{mM}$ ) for $90 \mathrm{~min}$ at $40{ }^{\circ} \mathrm{C}$ in the presence of $\mathrm{O}_{2}$ with continuous mixing at 400 rpm. Control samples were incubated in an identical matter in the absence of AAPH. The initial radical flux was estimated as $3 \times 10^{16}$ radicals $\mathrm{s}^{-1}$ at $40^{\circ} \mathrm{C}$, by use the first order rate constant for decomposition of AAPH [41]. Correction for the efficiency of escape of the initial carbon-centred radicals from the solvent cage [42], gives a flux of "free" radicals of $\sim 1.4 \times 10^{16}$ radicals s${ }^{-1}$ and therefore $1.38 \mu \mathrm{M} \mathrm{min}^{-1}$.

\subsection{SDS-PAGE and Western blotting}

Control and oxidized proteins samples $(16 \mu \mathrm{g}$ protein per well) were loaded on 4 $12 \%$ Bis-Tris acrylamide gels (Invitrogen, Carlsbad, CA), and electrophoresed at $200 \mathrm{~V}$ for 40 min. After electrophoresis, gels were either stained with colloidal Coomassie Blue [43] or blotted to nitrocellulose membranes using an iBlot2 system (Thermo Fisher; 25 V, 6 min). The membranes were then incubated with a rabbit primary polyclonal anti-NFK antibody, or

a murine monoclonal anti-dityrosine antibody (1:1000 diluted in 1\% BSA/TBST, 60 min, $\left.21^{\circ} \mathrm{C}\right)$ and secondary anti-rabbit-HRP or anti-mouse-HRP conjugates $(1: 5000$ in $1 \%$ 
BSA/TBST, overnight, $21^{\circ} \mathrm{C}$ ). Chemiluminescence from the ECL plus solution (Thermo Fisher) was monitored using a Syngene G:Box using an automatic shutter speed.

\section{$2.5 U V$-visible spectroscopy}

UV-Vis spectra were recorded, using a Shimadzu UV-1800 spectrometer, of solutions of Rose Bengal alone, G6PDH alone, and mixtures of Rose Bengal and G6PDH at the concentrations used for the photo-oxidation experiments (see above), to examine potential sensitizer - protein interactions.

\subsection{Enzyme activity}

G6PDH activity was monitored spectrophotometrically by following $\mathrm{NADP}^{+}(6 \mathrm{mM})$ reduction in the presence of glucose-6-phosphate $(100 \mathrm{mM})$ at $340 \mathrm{~nm}$ [44] in Tris- $\mathrm{HCl}$ buffer, $\mathrm{pH} 7.8$ at $30{ }^{\circ} \mathrm{C}$, with the rate calculated from the initial, linear part of the curve.

\subsection{Amino acid analysis by UPLC with fluorescence detection}

Control and treated proteins were hydrolyzed to free amino acids under conditions which conserves Trp residues [45]. $200 \mu \mathrm{L}$ of the reaction mixtures were transferred to glass hydrolysis vials, and the protein precipitated using $50 \mu \mathrm{L}$ of $50 \%$ aqueous trichloroacetic acid, washed twice with acetone, and dried using a stream of nitrogen gas. $150 \mu \mathrm{L}$ of $4 \mathrm{M}$ methanesulfonic acid containing $0.2 \% \mathrm{w} / \mathrm{v}$ tryptamine was added, $\mathrm{O}_{2}$ removed and samples incubated under vacuum at $110^{\circ} \mathrm{C}$ overnight using a Pico-Tag system. After cooling, the samples were neutralized with $\mathrm{NaOH}$, filtered through $0.2 \mu \mathrm{m}$ Pall Nanosep filters and 
diluted 4-fold with water. Diluted samples $(30 \mu \mathrm{L})$ were transferred to HPLC vials and subjected to UPLC using a Shimadzu Nexera system equipped with a SIL-30AC autosampler (with the samples kept at $4^{\circ} \mathrm{C}$ ) and a RF-20A xs fluorescence detector. Samples were derivatized by adding $10 \mu \mathrm{L}$ of OPA solution (Fisher) and incubated for $1 \mathrm{~min}$, before injection $(4 \mu \mathrm{L})$ on to a reversed phase column (Phenomenex Kinetex $2.6 \mu \mathrm{m}$ EVO $150 \times 3$ mm maintained at $40{ }^{\circ} \mathrm{C}$ ). Samples were eluted using a gradient (see Supplementary Table 1) of buffer A (100 mM sodium acetate $\mathrm{pH} 5.3,2.5 \%$ tetrahydrofuran, $20 \%$ methanol in water) and $\mathrm{B}(100 \mathrm{mM}$ sodium acetate $\mathrm{pH} 5.3,2.5 \%$ tetrahydrofuran, $80 \%$ methanol in water), at a flow rate of $0.8 \mathrm{~mL} \mathrm{~min}^{-1}$. Fluorescence was monitored using $\lambda_{\mathrm{ex}} 340 \mathrm{~nm}, \lambda_{\mathrm{em}} 440 \mathrm{~nm}$. Data analysis was carried using Shimadzu Lab Solutions Browser. Standards were run under identical conditions to identify eluting species, and to construct standard curves, from which concentrations were determined. To minimize concentration variations arising during the protein hydrolysis, the data were normalized to the concentration of Ala residues.

\subsection{Analysis of oxidation products by UPLC}

Protein samples were hydrolyzed and neutralized as described above, then analyzed as described previously [45]. Under the acidic conditions employed, NKF is hydrolysed to kynurenine [46] so the data represent the sum of these species. Samples $(4 \mu \mathrm{L})$ were injected on to reversed phase column (Phenomenex Kinetex $2.6 \mu \mathrm{m}$ EVO $150 \times 3 \mathrm{~mm}$ ) maintained at $30{ }^{\circ} \mathrm{C}$, and separated by gradient elution (Supplementary Table 1) using buffer A (100 mM sodium perchlorate, $\left.10 \mathrm{mM}, \mathrm{H}_{3} \mathrm{PO}_{4}\right)$ and buffer $\mathrm{B}\left(80 \%\right.$ aqueous methanol), at $0.8 \mathrm{~mL} \mathrm{~min}{ }^{-1}$ [45]. Product elution was monitored using 2 fluorescence detector channels parametrized according to the retention times of the products and their fluorescence maxima (for details see Supplementary Table 2). Data analysis was carried out with Shimadzu Lab Solutions 
Browser software. Retention times and concentrations were assigned by comparison to the authentic commercial standards, and standard curves generated from these. To compensate for any losses during processing, data are expressed relative to parent Tyr [45].

\subsection{Mass spectrometric analysis}

Protein $(20 \mu \mathrm{g})$ was dissolved in $20 \mu \mathrm{L} 8 \mathrm{M}$ urea, $50 \mathrm{mM}$ Tris- $\mathrm{HCl}$ at $\mathrm{pH}$ 8.0. Two $\mu \mathrm{L}$ of dithiothreitol (DTT, $450 \mathrm{mM})$ was added and incubated $\left(45 \mathrm{~min}, 21^{\circ} \mathrm{C}\right)$. Iodoacetamide (IAM, $4 \mu \mathrm{L}, 500 \mathrm{mM}$ ) was then added, and the samples incubated $\left(60 \mathrm{~min}, 21^{\circ} \mathrm{C}\right.$, in the dark). The alkylated protein sample was then divided into two fractions, for trypsin digestion in ${ }^{16} \mathrm{O}$ - and ${ }^{18} \mathrm{O}$-water as reported elsewhere [47]. Peptides from both digests were then subjected to solid-phase extraction on activated StageTip C18 reversed-phase discs and eluted with $10 \mu \mathrm{L} 60 \%$ acetonitrile, $0.1 \%$ trifluoroacetic acid [47]. The ${ }^{16} \mathrm{O}$ - and ${ }^{18} \mathrm{O}$-labelled materials were then dried down (Speedvac ${ }^{\mathrm{TM}}$ concentrator, 3 mins) and re-suspended in 10 $\mu \mathrm{L} \mathrm{H}_{2}{ }^{16} \mathrm{O}$ and $\mathrm{H}_{2}{ }^{18} \mathrm{O}$, respectively. These samples were mixed in $1: 1$ ratio immediately before analysis [47].

Samples were analyzed on a Q-Exactive Orbitrap (Thermo Fisher Scientific) coupled to an EASY-nLC 1000 liquid chromatography system (Thermo Fischer Scientific). Peptides were loaded onto a custom-made nanoLC column $(15 \mathrm{~cm}, \mathrm{C} 18,100 \AA, 1.9 \mu \mathrm{m}$ particle size, $75 \mu \mathrm{m}$ ID) packed into a Picofrit emitter (New Objectives) and eluted over 70 min using

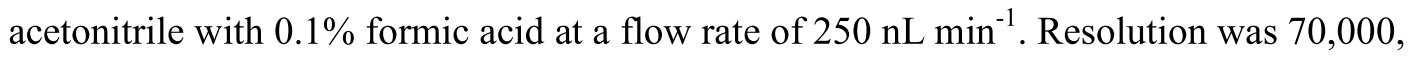
with an automatic gain control value of $3 \mathrm{e} 6$, maximum injection time of $20 \mathrm{~ms}$, and a scan range of 350 to $1500 \mathrm{~m} / \mathrm{z}$. MS/MS spectra were acquired in data-dependent mode (Top 10 method) with resolution of 35,000 , automatic gain control value of $1 \mathrm{e} 6$, and a injection time of $60 \mathrm{~ms}$. Data analysis was performed using MaxQuant $[48,49]$ with semi-specific tryptic 
constraints and a $1 \%$ peptide level false discovery rate. Carbamidomethyl of cysteine was used as a fixed modification while methionine oxidation and $\mathrm{N}$-terminal acetylation set as variable modifications. The "dependent peptides" feature was applied with a bin size of 0.0065 Da. Finally, the data was filtered in order to extract peptide-spectrum matches corresponding to established oxidative modifications using an in-house script and a list of 92 known oxidative and nitrosative mass shifts [50] as described elsewhere [51]. The modification occupancy at a particular primary structure position was calculated using an inhouse script by dividing the sum of signal intensities (area-under-the-curve) of all peptide spectral matches containing the modified position with the sum of the intensity of all peptide spectral matches containing the position (non-modified and modified). The relative abundance of a particular mass shift correlated to a particular type of amino acid was calculated as an average of the particular mass shift occupancy for all the relevant primary structure positions and normalized to $100 \%$. Modifications detected in the controls were quantified and subtracted from the treatment data, and modifications at cysteine were excluded from the dependent peptide analysis.

Analysis dedicated to identification of cross-linked peptides was performed on an Orbitrap Fusion mass spectrometer (Thermo Fisher) using three different methods:

A) A universal method characterized by a full MS scan and data-dependent MS/MS scans with top speed mode and a priority for the most intense precursors. Orbitrap resolution was set to 120000 , automatic gain control was $4 \mathrm{e} 5$, maximum injection time was $50 \mathrm{~ms}$, charge state was set from 2 to 7, monoisotopic peak determination was set as peptide, and intensity threshold was set up as 5e4. MS/MS scans of peptides subjected to HCD fragmentation (collision energy of $28 \%$ ) were detected in the Orbitrap detector, with resolution set to 120000 , automatic gain control target set to $5 \mathrm{e} 4$ and $80 \mathrm{~ms}$ injection time. MS/MS scans of peptides subjected to electron transfer dissociation fragmentation were also 
detected in the Orbitrap, with resolution of $120000,5 \mathrm{e} 4$ automatic gain control target and $200 \mathrm{~ms}$ injection time.

B) A data-dependent method where signals displaying mass shifts of 4, 6 and $8 \mathrm{Da}$ were selected for MS/MS. Only precursors with at least two $(+4$ and $+8 \mathrm{Da})$ or three $(+4,+6$ and $+8 \mathrm{Da}$ ) signals in the targeted group with intensities of at least $5 \mathrm{e} 3$ were selected. The subsequent scans were performed on the most intense ion in the pair. Orbitrap was selected for MS scans, with 3e5 automatic gain control target and $50 \mathrm{~ms}$ injection time. For MS/MS scans, automatic gain control target was $1 \mathrm{e} 5$ and maximum injection time of $105 \mathrm{~ms}$. The selected fragmentation type was high-energy collisional dissociation, with ions detected using the Orbitrap detector.

C) A targeted method based on an inclusion list with manually validated cross-linked peptides [51]. Similar conditions were used as in B), with the Orbitrap used as the detector with resolution of $120000,105 \mathrm{~ms}$ maximum injection time and automatic gain control target of $1 \mathrm{e} 5$.

Different fragmentation modes were used in the targeted methods: high-energy collisional dissociation with Orbitrap with 28\% collision energy (resolution 120000, 1e5 automatic gain control target, $105 \mathrm{~ms}$ injection time), electron transfer dissociation with Orbitrap detector (resolution 120000, 5e4 automatic gain control target, 200ms injection time) and finally electron-transfer and higher-energy collision dissociation, with Orbitrap detector, 25\% high-energy collisional dissociation supplemental collision energy (resolution 120000, 1e5 automatic gain control target, $105 \mathrm{~ms}$ injection time) [47]. MaxQuant (versions 1.5.2.8 and 1.5.5.1), GPMAW and MassAI were used for cross-link identification as described in [47]. MaxQuant was used to identify peptide retention times, charge states, mass errors and MS/MS events. GPMAW was used to obtain theoretical fragmentation patterns of cross-linking candidates for MS/MS data analysis; theoretical b, y, c, z fragment ions were 
calculated using the Protein MS X-link function. MassAI was used for identification and verification of cross-linked peptides in MS/MS using pre-defined possible cross-links including Tyr-Tyr, Trp-Tyr and Trp-Trp and appropriate mass losses. The search criteria included intra-protein, inter-protein and xlink modified peptides. Positive candidates were reevaluated manually by score and spectral analysis.

\subsection{Rendering of protein structures}

Protein structures were visualized using the program MolMol [52] and the G6PDH crystal structure data file 1DPG which lacks the N-terminal initiator methionine (M1). The numbering used throughout this publication assumes the presence of this methionine. Protein surfaces were calculated using Richard's model, with electrostatic potentials calculated using the 'simplecharge' algorithm (molecular dielectricity 2, solvent dielecticity 80, solvent radius $1.4 \AA$, salt concentration $100 \mathrm{mM}$, salt radius 2 , boundary size 10 ). Prior to calculations, the side chains of the PDB sequence were corrected for charge and N/C-terminality according to the user manual.

\subsection{Statistics}

Data are presented as means + standard deviations from at least three replicate independent experiments, with errors propagated when data are normalized to another parameter. Statistical analysis was carried out using the packages available in Excel with $P<$ 0.05 taken as indicating statistical significance.

\section{Results}




\subsection{Oxidative changes to G6PDH induced by singlet oxygen and peroxyl radicals}

SDS-PAGE was used to investigate potential intermolecular cross-linking and fragmentation as well as modifications influencing the size and structure of the protein, with the gels run under reducing conditions to eliminate contributions from reversible disulfide bond formation. Exposure of G6PDH to a complete system consisting of Rose Bengal (10 $\mu \mathrm{M}$ ), visible light and $\mathrm{O}_{2}$ in $70 \% \mathrm{D}_{2} \mathrm{O}$ (to enhance the lifetime of ${ }^{1} \mathrm{O}_{2}$ ) for 90 min resulted in the detection of material which appeared at lower and higher molecular mass compared to the parent protein (Fig. 1A, lane 2). Exposure of the protein to light in the absence of Rose Bengal, or Rose Bengal in the absence of light did not induce these changes (Fig. 1A, lanes 4,3 respectively). Incubation of G6PDH for 90 min without treatment did not induce any significant changes (data not shown), and examination of the samples by UV/visible spectroscopy showed little evidence of strong dye-protein interactions in non-irradiated samples (Supplementary Fig. 1). ROO $^{\bullet}$ formed by thermal decomposition of AAPH $(10 \mathrm{mM}$, $40{ }^{\circ} \mathrm{C}, 90 \mathrm{~min}$ ) result in a limited amount of lower molecular mass material (Fig. 1A, lane 6), when compared to protein incubated at $40{ }^{\circ} \mathrm{C}$ for the same time (Fig. 1A, lane 5). The latter observations are consistent with previous data [40].

Formation of intra-molecular cross-links, and modification of Tyr and Trp side-chains was examined by Western blotting using anti-di-Tyr and anti- $N$-formylkynurenine (antiNFK) antibodies on identical gels. Both antibodies showed a strong immunoreaction to G6PDH exposed to the Rose Bengal/light/O $\mathrm{O}_{2}$ system (Fig. 1B, lane 1; Fig. 1C, lane 1) when compared to samples exposed to incomplete oxidation systems (absence of Rose Bengal, absence of light, control incubations; data not shown). No immunoreactivity was detected with the parent protein using the anti-di-Tyr antibody (Fig. 1B, lane 3). Weak immunoreactivity against the parent protein was detected with the anti-NFK antibody (Fig. 
$1 \mathrm{C}$, lane 3), but this was markedly increased on exposure of the protein to the complete Rose Bengal/light $/ \mathrm{O}_{2}$ system for both the parent protein band, and material of lower and higher mass (Fig. $1 \mathrm{C}$, lane 1), consistent with both protein fragmentation and aggregation. With AAPH-derived $\mathrm{ROO}^{\bullet}$ no significant increased immunoreactivity was detected with either the anti-di-Tyr or anti-NFK antibodies (Fig. 1B, lane 2; Fig. 1C, lane 2).

\subsection{Effect of oxidation on enzyme activity}

Both the complete Rose Bengal/light $/ \mathrm{O}_{2}$ system and AAPH-derived ROO $\bullet$ significantly decreased G6PDH activity (Fig. 1D), with the photo-sensitized oxidation system completely abolishing enzymatic activity, and $\mathrm{ROO}^{\bullet}$ decreasing this by $\sim 30 \%$.

\subsection{Quantification of loss of parent amino acids}

Oxidative modifications of G6PDH elicited by the Rose Bengal/light/ $\mathrm{O}_{2}$ system and AAPH-derived $\mathrm{ROO}^{\bullet}$, were investigated by both UPLC and MS, with the former giving data on total changes, and MS providing information about changes at specific sites.

Supplementary Tables 3 and 4 provide a complete list of the modified peptides detected by MS, the detected mass shifts and the position of these modifications in the protein sequence, for both oxidation systems. The MS approach provided good sequence coverage (Fig. 2A,B) of both the native and modified protein $\left(\sim 89 \%\right.$ after ${ }^{1} \mathrm{O}_{2}$ treatment, $93 \%$ after AAPH treatment). However, peptides containing 3 (of the 7) Trp residues (Trp 248, Trp 434 and $\operatorname{Trp}$ 441) were not recovered after ${ }^{1} \mathrm{O}_{2}$-induced oxidation, limiting the assessment of $\operatorname{Trp}$ modification by MS. 
Analysis of the parent protein by amino acid analysis using UPLC gave an amino acid composition in accordance with that expected from the protein sequence in the protein database (PDB) structure 1DPG (cf. data in Fig. 2), with the following abundances: Trp 1.4 $\%$, Tyr $4.3 \%$; His $1.2 \%$ and Met $2.0 \%$. The Rose Bengal $/$ light $/ \mathrm{O}_{2}$ system resulted in extensive modification of Trp residues as detected by both UPLC and MS, with 54 and $62 \%$ loss of unmodified residues, respectively (Fig. 3A). For His, a marked loss was detected by UPLC (62\% loss), but a much lower extent of loss was detected by MS (15\%).

A similar phenomenon was observed with other amino acids, with a greater extent of modification detected by UPLC Tyr (UPLC: $9 \%$, MS: $4 \%$ ), Val (UPLC: $7 \%$, MS: $1 \%$ ) modification and Met (UPLC: $23 \%$, MS: $58 \%$ ) (Fig. 3A). Met oxidation was included as a variable modification in the MS analysis due to the known generation of Met sulfoxide from Met during sample preparation and / or ionization in the MS source. Reasons for these differences are addressed in the discussion. All other amino acids (with the exception of Cys, cystine and proline, which cannot be measured by the UPLC technique employed) were not decreased significantly (i.e. by $<\sim 5 \%$ ). These data indicate that photo-sensitized oxidation results in significant, but selective damage at Trp, His, Met and Tyr, consistent with previous data [34,53]. In contrast, incomplete photo-sensitized oxidation systems (i.e. G6PDH exposed to Rose Bengal alone, or light alone) resulted in minimal extents of protein modification, suggesting that ${ }^{1} \mathrm{O}_{2}$ generated by Rose Bengal is the key intermediate in the complete photooxidation system.

Analogous experiments with AAPH-derived $\mathrm{ROO}^{\bullet}$ resulted in a broader pattern of modifications, and a lower overall extent of damage (Fig. 3B), with the overall extents of loss, for the two methods, being: Trp (UPLC $18 \%$, MS $20 \%$ ), His (UPLC $8 \%$, MS $2 \%$ ), Met (UPLC $14 \%$, MS $52 \%$ ), Tyr (UPLC $9 \%$, MS $2 \%$ ) and Val (UPLC $10 \%$, MS $0.03 \%$ ). A low extent of loss was also detected by UPLC for Asn/Asp (which are detected as a single 
peak by UPLC due to acid-catalyzed conversion of Asn to Asp), Ile, Phe and Thr (Fig. 3B). An increase in Gly concentration of $\sim 15 \%$ was also detected by UPLC consistent, with the formation of this amino acid via side-chain loss from other amino acids (see, e.g., [54-56]).

\subsection{Quantification of specific Trp and Tyr oxidation products by UPLC}

Formation of $o$ - and $m$-Tyr (oxidation products of Phe), kynurenine (Kyn) and NFK (from Trp), and DOPA and di-Tyr (from Tyr) was quantified by UPLC with fluorescence detection, and comparison to standard curves generated using authentic standards. For the photo-sensitized oxidation system, $\sim 13 \%$ of the Trp present in the parent protein $(13.3 \mathrm{pmol}$ per injection) was converted to NFK and Kyn (1.75 pmol), with this accounting for $24 \%$ of the identified Trp-derived products (Fig. 4A). These products therefore account for only a relatively low percentage of the total Trp lost, with the fate of $41 \%$ of the initial $\operatorname{Trp}$ (and 76 $\%$ of that consumed) remaining unknown (but see also below). For AAPH-derived peroxyl radicals, only a small fraction of the initial Trp present $(2 \%, 0.2$ pmol $)$ was detected as NFK and Kyn, with these two products accounting for $11 \%$ of the Trp lost, with $16 \%$ of the initial $\operatorname{Trp}$ (and $89 \%$ of the amino acid lost) converted to unknown species. No significant formation of $o$ - and $m$-Tyr from Phe was detected with either oxidation system (Fig. 4B). For Tyr, a low level ( $0.2 \%$ conversion, $0.08 \mathrm{pmol})$ of the initial Tyr was detected as di-Tyr (representing $2 \%$ of the Tyr lost) for the photo-sensitized oxidation system, but no significant formation of DOPA were detected. For the $\mathrm{ROO}^{\bullet}$ system, no significant formation of DOPA or di-Tyr were detected over the corresponding controls (Fig. 4).

\subsection{Detection and quantification of specific Trp and Tyr oxidation products by MS.}


Detection and summation of the various Tyr and Trp modifications observed in the MS analysis provided evidence for the same oxidation products detected by UPLC, and also additional species (Figs. 4,5). For the photo-oxidation system, significant new peaks were observed with mass increases of $+4 \mathrm{Da}$ (assigned to Kyn) and $+32 \mathrm{Da}$ (consistent with the addition of 2 oxygen atoms and a di-oxygenated species [57]) were detected. The former accounted for $13 \%$ of the initial Trp (and $22 \%$ of the Trp lost), whereas the latter accounted for $44 \%$ of the initial $\operatorname{Trp}$ (and $71 \%$ of the Trp lost). For AAPH-derived ROO ${ }^{\bullet}$ evidence was obtained for species with $+4 \mathrm{Da}$ (Kyn, accounting for $4 \%$ of the initial Trp and $19 \%$ of the Trp products), $+16 \mathrm{Da}$ (consistent with a mono-oxygenated product, accounting for $2.5 \%$ of the initial Trp, and $12 \%$ of the Trp products), and $+32 \mathrm{Da}$ (di-oxygenated species, accounting for $12 \%$ of the initial Trp and $61 \%$ of the Trp products). These data are however limited to the 4 Trp residues detected after photo-sensitized oxidation.

\subsection{Analysis of oxidation at specific residues in protein sequence}

The above MS analysis was extended to determine modifications at specific residues within the G6PDH sequence. For the photo-oxidation system, mass shifts of $+4 \mathrm{Da}$ (assigned to Kyn, and accounting for $6-18 \%$ of the parent Trp) and $+32 \mathrm{Da}(34 \%-60 \%$ of the parent Trp) were the abundant modifications detected on the observed Trp-containing peptides that could be detected and analyzed (see Fig. 5 and above). A further mass shift of $+48 \mathrm{Da}$ (consistent with addition of 3 oxygen atoms) was identified on Trp 203 (accounting for $6 \%$ of the oxidation at this residues) and $\operatorname{Trp} 402$ (6\% of oxidation at this site). The highest overall extent of oxidation (i.e. highest \% conversion to products) was detected for Trp 402 (84\% modification), with modification of Trp 203 (49\%), Trp 328 (58\%) and Trp 482 (57\% modification) being more limited. 
AAPH-induced oxidation gave rise to lower overall levels of modification (see also above) with modification at 5 of the observed Trp residues (203, 248, 328, 441 and 482) being $0-20 \%$ of the initial Trp levels. In contrast, Trp 328 was oxidized to a moderate extent (29\%), and Trp 402 was heavily modified (61\%). Four of the Trp residues (328, 402, 441, 482) provided evidence for the $+4,+16$ and +32 mass shifts. Of the three remaining, $\operatorname{Trp} 203$ was only modified with +32 , $\operatorname{Trp} 248$ was not found in a modified state, and Trp 434 had +4 and +32 Da modifications.

The MS analysis also provided evidence for low levels of modification at other amino acid residues including His 39, Lys 38, and Lys 266 (as +16 Da, mono-oxygenated species) and Lys 129 and Lys 266 as -1 Da species (ascribed to loss of the side-chain amine and aldehyde formation $[58,59])$.

\subsection{Mass spectrometric identification of protein cross-links}

The presence of cross-links was investigated by making use of the addition mass differences present in cross-linked peptides containing two carboxyl termini after trypsincatalyzed protein digestion in $\mathrm{H}_{2}{ }^{18} \mathrm{O}$ compared to $\mathrm{H}_{2}{ }^{16} \mathrm{O}$, which produces distinctive patterns of peaks differing by $4 \mathrm{Da}$ (i.e. +4 compared to $+8 \mathrm{Da}$; $[25,47])$ as a result of the incorporation of $4{ }^{18} \mathrm{O}$ atoms at the two $\mathrm{C}$-termini of the cross-linked peptide), indicative of the presence of the cross-link. Fig. 6A illustrates the fragmentation spectrum of a cross-linked peptide (FVDAISAVYTADK) (APLETYK), containing a cross-link between two Tyr residues (indicated by the underscoring between the two residues indicated in bold type). The ions indicated in blue correspond to the fragmentation of the peptide FVDAISAVYTADK, whilst those in red correspond to the fragmentation of APLETYK. The mass loss of 2.01 compared to the sum of the parent sequences is consistent with a di-Tyr cross-link. The good 
coverage of fragment ions from each component peptide is consistent with the proposed identity of the peptides involved, and the position of the cross-link site. The fragments $b_{1}$ to $\mathrm{b}_{8}$, and $\mathrm{y}$ ions from $\mathrm{y}_{1}$ to $\mathrm{y}_{4}$ (indicated in blue) from FVDAISAVYTADK part exclude possible cross-links outside the sequence YTAD. The $b_{2}$ to $b_{5}$ and $y_{1}$ ions (indicated in red) from APLETYK unambiguously locate the link position to the Tyr residue. The cross-link in this species is therefore assigned to Tyr 451-Tyr 461.

Fig. 6B illustrates a second cross-linked peptide detected in the sequences (DYIK) (FGNPIFDAAWNK). The overall mass loss of 2.01 Da compared to the sum of the masses of the two parent peptides is consistent with the loss of two hydrogen atoms in the proposed Tyr-Trp link. The coverage of peptide ions that contain the cross-link site, provides information on the nature of the two peptides involved and the site of the cross-link. The detection of $y_{3}$ to $y_{8}$, and $b_{2}$ to $b_{8}$ (indicated in blue) from FGNPIFDAAWNK, and the $y_{1}$ and $\mathrm{y}_{2}$ ions (indicated in red) from DYIK, narrows the potential cross-link sites to the $\mathrm{W}$ and $\mathrm{N}$ residues in the first peptide, and $\mathrm{D}$ and $\mathrm{Y}$ in the second peptide, and the nature of these residues strongly suggests that a cross-link between $\operatorname{Trp}(\mathrm{W}) 203$ and Tyr (Y) 207. After ${ }^{1} \mathrm{O}_{2}$ exposure, di-Tyr cross-links in the peptide pairs (YFVR) (NAAFNALKIYDEAEVNK) involving Tyr 276 and Tyr 284, and (FVDAISAVYTADK) (APLETYK) involving Tyr 451 and Tyr 461 were identified (cf. Fig. 6). Moreover, peptides with Trp-Tyr crosslinks have been identified after both ${ }^{1} \mathrm{O}_{2}$ and $\mathrm{ROO}^{\bullet}$ exposure, with (DYIK) (FGNPIFDAAWNK) involving a linkage between Trp 203 and Tyr 207 observed with ${ }^{1} \mathrm{O}_{2}$, and (YFVR) (WEGVPFYVRSGK), linking Trp 328 and Tyr 284, with ROO` (data not shown).

\section{Discussion}

In this study we have investigated the oxidation of the key cellular metabolic enzyme glucose-6-phosphate dehydrogenase (G6PDH) induced by photo-sensitized oxidation 
reactions initiated by Rose Bengal, and $\mathrm{ROO}^{\bullet}$ derived from the AAPH thermolysis. Rose Bengal generates high yields of ${ }^{1} \mathrm{O}_{2}$ on illumination with visible light [60], which results in predominantly Type II photo-oxidation reactions [34]. However, Type 1 mechanisms involving other excited states, or photo-ionization reactions, can occur as a result of the formation of dye-protein complexes (cf. data in [61-63]). The bathochromic wavelength shift of $2 \mathrm{~nm}$ of the Rose Bengal maximum observed in the current study in the presence of G6PDH (Supplementary Fig. 1) is consistent with weak dye-protein complex formation and hence potential contributions from Type I photochemistry, though this shift is very small compared to those detected with Rose Bengal and human serum albumin (up to $14 \mathrm{~nm}$ ) [61]. This previous study also investigated the effect of Rose Bengal binding to the protein on ${ }^{1} \mathrm{O}_{2}$ mediated infra-red phosphorescence, with the presence of HSA neither modifying the initial phosphorescence intensity, nor its rise time. On the basis of these data, it is concluded that the major oxidant formed by the photosystem is ${ }^{1} \mathrm{O}_{2}$, while the AAPH system will mainly yield $\mathrm{ROO}^{\bullet}$, though contributions from initial carbon-centered species, and downstream alkoxyl radicals $\left(\mathrm{RO}^{\bullet}\right)$ which are major intermediates at low $\mathrm{O}_{2}$ levels and low target concentrations, respectively, cannot be completely excluded [64].

The oxidant concentrations used have been estimated to be of the same order of magnitude, facilitating comparison between these systems. On the basis of the first order rate constant for decomposition of AAPH [41], the initial radical flux has been estimated as $3 \mathrm{x}$ $10^{16}$ radicals s ${ }^{-1}$ at $40{ }^{\circ} \mathrm{C}$, with correction of this value for the efficiency of escape of the initial carbon-centered radicals from the solvent cage [42], giving a flux of freely diffusible radicals of $\sim 1.4 \times 10^{16}$ radicals s${ }^{-1}\left(\sim 1.4 \mu \mathrm{M} \mathrm{min}^{-1}\right)$. For the corresponding photo-oxidation system, the photon flux was determined as $2 \times 10^{16}$ photons $\mathrm{s}^{-1}$ using a $\mathrm{Ru}(\mathrm{BPY})_{3} \mathrm{Cl}_{2} /$ diphenylanthracene actinometer [39], with the quantum yield for ${ }^{1} \mathrm{O}_{2}$ formation by Rose Bengal in aqueous buffer reported as 0.75 [60]. 
We hypothesized that oxidation of Tyr and Trp in G6PDH, in addition to His, Cys and Met, would be relevant to the functional outcomes, due to their ease of oxidation, and their high rate constants for reaction with ${ }^{1} \mathrm{O}_{2}$ and $\mathrm{ROO}^{\bullet}[8,34,40,65-67]$. G6PDH is relatively rich in Trp and Tyr residues (cf. abundance levels of $1.1 \%$ and $2.9 \%$ for Trp and Tyr respectively for total intracellular proteins, compared to 1.4 and 4.3\% for G6PDH [68]). Previous studies have provided strong evidence for oxidation at these residues $[38,40,57,67,69,70]$. The data reported herein support the quantitative significance of oxidation at these sites, but also indicate that there are significant differences in the extent of oxidation, the products formed, and the consequences of reaction at these residues.

The SDS-PAGE and Western blot experiments have provided evidence for the formation of higher (e.g. aggregated, with ${ }^{1} \mathrm{O}_{2}$ exposure) and lower mass (e.g. fragmented) material, intramolecular Tyr-Tyr and Tyr-Trp cross-links, and significant levels of products derived from Met, Trp and Tyr. Lower levels of oxidation were also detected at other residues (e.g. His), particularly with $\mathrm{ROO}^{\bullet}$. The overall extent of oxidation was quantitatively greater with ${ }^{1} \mathrm{O}_{2}$-mediated oxidation, than $\mathrm{ROO}^{\bullet}$, as indicated by both the UPLC and MS data (see below). These changes appear to be reflected in the residual enzyme activity detected under identical reaction conditions, with ${ }^{1} \mathrm{O}_{2}$ inducing complete loss of G6PDH activity compared to only $\sim 30 \%$ loss for the ROO ${ }^{\bullet}$ system.

Oxidation at Trp, Tyr and His residues was quantified by two independent and complementary methods: UPLC, to detect total loss of amino acid residues and total amounts of Trp and Tyr oxidation products, and MS to investigate the nature and degree of oxidation at individual amino acids within the protein sequence. The data obtained indicate the strength of using these methods in tandem, as the combination yields a clearer picture of the oxidation processes that occur. In particular, incomplete coverage of the protein (missing peptides), and 
problems in quantifying low levels of change at specific sites limits the MS approach, whereas the UPLC approach cannot give positional data.

These two approaches consistently indicate that Trp residues are major targets for both ${ }^{1} \mathrm{O}_{2}$ and $\mathrm{ROO}^{\bullet}$, with the former modifying $~ 58 \%$ of these residues (54 \% by UPLC analysis, $62 \%$ by MS) compared to $\sim 19 \%$ after ROO ${ }^{\bullet}$ treatment (UPLC $18 \%$, MS $20 \%$ ). This high degree of modification is in line with the reported high reactivity of Trp residues with ${ }^{1} \mathrm{O}_{2}$ (both free and in proteins, though the latter is environment sensitive) with $k_{2} \sim 3 \mathrm{x}$ $10^{7} \mathrm{M}^{-1} \mathrm{~s}^{-1}[65,67]$. Trp is also expected to be a good target for $\mathrm{ROO}^{\bullet}$ (cf. a one-electron reduction potential of $1000 \mathrm{mV}$ for $\mathrm{ROO}^{\bullet}$, compared to $\sim 840 \mathrm{mV}$ and $\sim 930 \mathrm{mV}$ for Trp and Tyr, respectively [71]), though absolute rate constants for $\mathrm{ROO}^{\bullet}$ reactions (where $\mathrm{R}=$ alkyl or lipid chain) do not appear to have been reported. However, the related (highly reactive) species $\mathrm{CCl}_{3} \mathrm{OO}{ }^{\bullet}$ reacts with free Trp with $k_{2} 8.5 \times 10^{7} \mathrm{M}^{-1} \mathrm{~s}^{-1}$, and also targets Trp in proteins (e.g. lysozyme [72]), suggesting that AAPH-derived $\mathrm{ROO}^{\bullet}$ will also target these residues. The UPLC product analyses reported here are consistent with this picture, with significant formation of NFK/Kyn detected on ${ }^{1} \mathrm{O}_{2}$ exposure $(24 \%$ of Trp products detected, $13 \%$ of the parent Trp lost). The MS analyses also provided evidence for Kyn formation by ${ }^{1} \mathrm{O}_{2}$ (+4 Da species: $13 \%$ of parent, $22 \%$ of the Trp-derived products). The $+32 \mathrm{Da}$ species detected by MS is consistent with NFK or other dioxygenated products (e.g. peroxides or diols), with these species accounting for $44 \%$ of the parent Trp lost. Due to their stability, it is likely that these are diols rather than peroxides (cf. data in $[57,73]$ ). However, it should be noted that a significant proportion of the Trp lost (76\%) remains unknown, which may be indicative of peroxide formation and subsequent decomposition to alternative products $[57,73,74]$. With AAPH, a smaller fraction (2\%) of the parent Trp was converted to NFK/Kyn, (6\% of the Trp-derived products), and significant levels of +32 Da species $(12 \%$ of parent lost) and a product with a mass of $+16 \mathrm{Da}(2.5 \%$ of parent $)$ were also detected. The 
+16 Da species may be an alcohol or phenol generated by direct ring hydroxylation, or via degradation of an initial hydroperoxide as observed with model peptides [57]). Compared to the ${ }^{1} \mathrm{O}_{2}$ system, a smaller proportion (16\%) of the Trp lost is unaccounted for.

The Trp oxidation is not spread equally over the 7 Trp residues present in the protein. With the ${ }^{1} \mathrm{O}_{2}$-system, despite considerable efforts, 3 of the residues were unable to be detected after photo-oxidation. For the 4 Trp detected, the extent of modification was 49 - 84 $\%$, indicating that some Trp residues are more sensitive to oxidation than others. This may be a kinetic effect (cf. data on the variation in $k_{2}$ for Trp oxidation [67]), or other factors, including rapid repair / damage transfer reactions. Previous studies have reported rapid electron transfer within proteins and peptides to Trp radicals [75-78]. However, whilst this may be a major process for Trp radicals, whether such repair processes also occur with ${ }^{1} \mathrm{O}_{2}$ adducts to Trp remains is unclear. The major mass shifts detected were $+32 \mathrm{Da}(34 \%-60 \%$ Trp conversion) and $+4 \mathrm{Da}(6-17.5 \%$ Trp conversion). Formation to a +48 species (consistent with the addition of 3 oxygens) was also identified at W 203 (6\%) and W 402 (6 $\%$ ). In contrast, $\mathrm{ROO}^{\bullet}$ induced lower degrees of modification, with only W $328(29 \%)$ and W 402 (60\%) extensively modified. With regard to the products formed, significant formation of a $+16 \mathrm{Da}$ species was detected at some residues $(11 \%$ at $\mathrm{W} 402,5 \%$ at $\mathrm{W} 328$, consistent with single oxygen atom addition, in addition to +4 and +32 Da species. Examination of protein structure indicates that the most heavily oxidized residue for both oxidants (W402) is the most surface exposed (Fig. 7) consistent with this being a critical factor.

UPLC analyses (but not MS) indicate a high degree of His modification with ${ }^{1} \mathrm{O}_{2}(62$ $\%$ loss compared to $15 \%$ by MS), despite the low abundance of this residue (1.2\%). This high value is consistent with the high $k_{2}$ value $\left(3.2-9 \times 10^{7} \mathrm{M}^{-1} \mathrm{~s}^{-1}\right)$ reported for reaction of ${ }^{1} \mathrm{O}_{2}$ with free His at $\mathrm{pH} \sim 7$ [65]. The UPLC data is likely to be a more reflection of the overall 
extent of modification, as the MS approach requires complete coverage of the protein to assess total loss, and a detailed knowledge of the products formed, to yield high quality data. Notably, no 2-oxo-His formation were detected by MS, possibly reflecting the instability of this compound, which undergoes rapid ring opening and further degradation $[79,80]$, or cross-link formation via His-His linkages [17-19]. Furthermore, the multiplicity of products generated from His by ${ }^{1} \mathrm{O}_{2}[17,18,81]$ may be a significant problem. However, the MS analyses do indicate significant levels of oxidation at a single His residue, H79. The ROO system induced lower levels of His modification, with significantly lower levels detected by MS compared to UPLC (UPLC $8 \%$, MS $0.2 \%$ ), probably for similar reasons to those outlined above.

Significant loss of Met residues was detected with both oxidants $\left({ }^{1} \mathrm{O}_{2}\right.$ : UPLC $23 \%$, MS $58 \%$; ROO ${ }^{\bullet}$ UPLC $14 \%$, MS $53 \%$ ). For the ROO ${ }^{\bullet}$ system a concomitant increase in methionine sulfoxide levels was detected (from $\sim 37 \%$ in controls to $62 \%$ in treated), but this was not evident for ${ }^{1} \mathrm{O}_{2}$, although this species has been reported to be a major product of Met oxidation by ${ }^{1} \mathrm{O}_{2}$ [82]. The MS data needs to be treated with caution, since oxidation can occur during proteolytic digestion and ionization, with the N-terminal Met (M1) detected in an oxidized (+16 Da) form in all samples, including controls. Despite this, the MS analysis shows higher levels of Met modification in the oxidized samples with subtraction of the control data indicating $18-90 \%$ conversion of Met to the sulfoxide, at individual sites, on oxidant exposure. Studies with other oxidants, including $\mathrm{HO}^{\bullet}[83-85]$ have provided evidence of complex mechanisms for Met, with only a limited extent of conversion to the sulfoxide. The mechanisms of $\mathrm{ROO}^{\bullet}$ - and ${ }^{1} \mathrm{O}_{2}$ - mediated Met oxidation on proteins are incompletely understood, though it has been established that AAPH-derived $\mathrm{ROO}^{\bullet}$ can oxidize Met on other proteins $[85,86]$. The complexities of these reactions, or over-oxidation, may explain the lack of methionine sulfoxide detection by UPLC in the ${ }^{1} \mathrm{O}_{2}$ reactions. 
Oxidation at $\mathrm{Val}$, and to a lesser extent other amino acids with bulky alkyl side-chains (e.g. Ile), was also detected, with the extent of modification at Val induced by ${ }^{1} \mathrm{O}_{2}$ being $7 \%$ by UPLC and $1 \%$ by MS, and for ROO $10 \%$ by UPLC and $0.05 \%$ by MS. This may reflect the relatively high abundance of these residues (e.g. $5.8 \%$ for Val). Direct oxidation of alkyl side-chains by ${ }^{1} \mathrm{O}_{2}$ is unlikely [34], and therefore this may arise via secondary reactions of initial photo-products such as hydroperoxides formed from Trp, Tyr and His residues, involving decomposition to radicals (cf. data in $[17,38,57]$ ), or oxidation via alternative species (e.g. triplet states).

The extent of Tyr modification was relatively modest $\left({ }^{1} \mathrm{O}_{2}\right.$ : UPLC $9 \%$, MS $3 \%$; ROO $^{\bullet}$ : UPLC $9 \%$, MS $2 \%$ ), especially given the higher abundance of this species compared to $\operatorname{Trp}\left(\sim 3\right.$-fold). Significant modification was however identified at Tyr 416 with both ${ }^{1} \mathrm{O}_{2}$ and ROO $^{\bullet}$. Previous studies on a G6PDH Tyr $416 \rightarrow$ Phe mutant indicate however, that this residue is not involved in substrate binding, and mutation does not significantly modulate enzyme activity [87]. A significant product of the oxidized Tyr residues on ${ }^{1} \mathrm{O}_{2}$ oxidation, appears to be di-Tyr, with this representing $0.2 \%$ of the parent. In contrast, little di-Tyr formation was detected with $\mathrm{ROO}^{\bullet}$, and no formation of 3,4-dihydroxyphenylalanine (DOPA) was detected with either oxidant. The other methods employed (Western blotting, MS) corroborate the diTyr findings qualitatively, though each method has limitations.

As dimers and higher oligomers were detected both here and previously [40], and evidence for di-Tyr formation was obtained using both antibody and UPLC methods after oxidation with ${ }^{1} \mathrm{O}_{2}$, the site(s) of this cross-link within the protein were examined by MS. This methodology has allowed four candidates, with high percentage $b$ - and $y$ - ion coverage, to be identified including di-Tyr cross-links involving Tyr 276 / Tyr 284 and Tyr 451 / Tyr 461 with ${ }^{1} \mathrm{O}_{2}$ (cf. Fig. 6), and Trp-Tyr crosslinks after ${ }^{1} \mathrm{O}_{2}$ and $\mathrm{ROO} \bullet$ exposure (Trp 203 / Tyr 207 with ${ }^{1} \mathrm{O}_{2}$; $\operatorname{Trp} 328 / \operatorname{Tyr} 284$ with $\mathrm{ROO}^{\bullet}$ ). Examination of the protein structure shows that 
the residues in each linkage are in proximity to each other (Fig. 8), and that at least one of the reaction partners is surface-accessible in each pair.

For the Tyr 276 / 284 pair (Fig. 8A), the structural coordinates indicate that the residues are in close contact and positioned in an orientation that would favor cross-linking, with the distance between the respective $\mathrm{C} 2$ or $\mathrm{C} 5$ side-chain atoms being $\sim 4.2 \AA$. This species may therefore represent an intramolecular cross-link, and be in accordance with the anti-di-Tyr immunoreactivity detected in the Western blotting and UHPLC experiments after ${ }^{1} \mathrm{O}_{2}$ exposure. For the Tyr $451 / 461$ pair (Fig. 8B), the $\mathrm{C} 2 / \mathrm{C} 5$ side-chain atoms are $\sim 11.7 \AA$ apart. The Tyr 461 residue does not appear to have significant surface-accessibility, and direct contact between these two residues is likely to be hindered by a beta-sheet structure between Tyr 451 and Tyr 461. Consequently, it is unclear whether this cross-link occurs within the same protein, or between different molecules: either possibility would appear to require significant flexibility of the protein structure to allow cross-link formation (i.e. movement of the beta-sheet to allow an intra-molecular link to be generated, or flexibility to allow surface accessibility of Tyr 461 to form an inter-molecular linkage.

For the Trp/Tyr linkages, the Trp 207 / Tyr 203 pair are in close contact, with Trp207 being surface accessible, though the crystal structure data suggest that side-chain rotation or motion would be required to bring the side-chains in close contact given a distance of $\sim 11.7$ $\AA$ between the $\mathrm{C} 2 / 5$ positions on the Tyr phenolic ring and the indole nitrogen of the Trp. The Trp 327 / Tyr 284 pair are $\sim 16.9 \AA$ apart (C2/5 of Tyr to indole N), a distance which may still allow internal cross-linking (cf. data from studies using amine-selective cross-linking agents [88]), however Tyr284 has a Tyr276 as alternative reaction partner. The residue-to-residue and surface accessibility data for these species appear to be restricted, suggesting a requirement for structural flexibility or motion to generate this cross-link. 
Both the Tyr-Tyr and Trp-Tyr cross-link may arise via radical-radical reactions. Existing data on facile and rapid radical transfer between Tyr and Trp supports this conclusion [75-78], and evidence has been reported previously for other Tyr-Tyr and Tyr-Trp cross-links in proteins $[14,16]$. The presence of additional types of cross-link is likely to account, at least in part, for a previous report in which the levels of di-Tyr detected were insufficient to account quantitatively for the extend of cross-linking, resulting in the proposal that Trp oxidation may play a significant role [40]; the current data support this conclusion.

The loss of enzyme activity seen with both oxidants cannot be ascribed unequivocably to any of the observed modifications, as multiple modifications were detected in each case. However, site-specific mutagenesis studies suggest that some of the detected modifications may modulate activity. Thus Met 185 , which was highly modified by $\mathrm{ROO}^{\bullet}$, is located near the binding site and the catalytic His/Asp dyad [89]. Met 146 and 327, which were strongly affected by ${ }^{1} \mathrm{O}_{2}$, are also adjacent to binding regions, and oxidation of these residues may therefore perturb these sites. Other residues that were detected in modified forms (e.g. Tyr 416 and 179, Ala 84) also occur in binding regions, or in close proximity to these, may also contribute to the observed loss of enzyme function [87,90,91].

Overall, these data indicate that oxidation initiated by ${ }^{1} \mathrm{O}_{2}$ and $\mathrm{ROO}^{\bullet}$ can induce functional (loss of enzyme activity) and structural changes (formation or cross-links and fragments, chemical alteration of side-chains) of G6PDH, the critical pace-making enzyme of the pentose phosphate pathway. These observations complement data on the loss of G6PDH activity induced by metal-ion catalyzed oxidation [92]. This enzyme is a major source of NADPH within cells and therefore critical to the control and prevention of redox damage, with deficiency, or loss of G6PDH activity known to contribute to disease $[31,32]$. Damage to G6PDH and loss of activity may result in an increasing spiral of enzyme degradation, reduced capacity to regenerate NADPH, decreased antioxidant defense activity 
and increasing oxidative damage. The data presented here indicate that Trp and Met oxidation are major processes with conversion of these residues to multiple products. Damage also occurs at His and Tyr residues. The observed damage is non-uniform, with some residues much more susceptible to modification than others, with this resulting in specific Tyr-Tyr and Trp-Tyr cross-links. Whether these cross-links directly affect enzyme activity is unclear and remains to be elucidated. These data on the effects of $\mathrm{ROO}^{\bullet}$ on $\operatorname{Trp}$ residues are consistent with a previous report indicating that APPH-derived radicals can give rise to efficient inactivation and loss of 4 Trp residues in lysozyme [93] suggesting that this may be a common mechanism of protein modification and loss of enzyme activity.

This study contributes a greater understanding of the chemistry of glucose-6phosphate dehydrogenase oxidation and its loss of activity. The central role of this enzyme in the pentose phosphate pathway and its rate-limiting activity, are consistent with the hypothesis that modification of the activity of this enzyme and pathway are linked to the development and progression of human disease. The findings reported here suggest that further studies into a potential causal link between protein oxidation and inhibition of the associated metabolic pathway in cells and in vivo are warranted, as this may provide clues towards new treatment strategies.

\section{Acknowledgements}

The authors are grateful for financial support from the Novo Nordisk Foundation (grant: NNF13OC0004294 to MJD) and FONDECYT (Grant: 1141142 to C.L.-A.). The Orbitrap mass spectrometers used in this study were granted by the Danish Council for Independent Research | Natural Sciences (grant number 11-106246) and the Velux Foundation. The Danish Research Foundation, Nordic Bioscience A/S and Technical 
University of Denmark are acknowledged for joint PhD scholarships to MM and MR. The authors thank Lis Frandsen, KU, for help with the actinometry measurements. 


\section{References}

[1] Halliwell, B.; Gutteridge, J. M. C. Free radicals in biology \& medicine. Oxford: Oxford University Press; 2015.

[2] Davies, M. J. Protein oxidation and peroxidation. Biochem. J. 473 (2016) 805-825

[3] von Sonntag, C. The chemical basis of radiation biology. London: Taylor and Francis; 1987.

[4] Alvarez, B.; Radi, R. Peroxynitrite reactivity with amino acids and proteins. Amino Acids 25 (2003) 295-311.

[5] Ferrer-Sueta, G.; Radi, R. Chemical biology of peroxynitrite: Kinetics, diffusion, and radicals. ACS Chem Biol 4 (2009) 161-177.

[6] Pattison, D. I.; Davies, M. J. Reactions of myeloperoxidase-derived oxidants with biological substrates: Gaining insight into human inflammatory diseases. Curr. Med. Chem. 13 (2006) 3271-3290.

[7] Hawkins, C. L.; Pattison, D. I.; Davies, M. J. Hypochlorite-induced oxidation of amino acids, peptides and proteins. Amino Acids 25 (2003) 259-274.

[8] Davies, M. J. Singlet oxygen-mediated damage to proteins and its consequences. Biochem. Biophys. Res. Commun. 305 (2003) 761-770.

[9] Karimi, M.; Ignasiak, M. T.; Chan, B.; Croft, A. K.; Radom, L.; Schiesser, C. H.; Pattison, D. I.; Davies, M. J. Reactivity of disulfide bonds is markedly affected by structure and environment: Implications for protein modification and stability. Sci Rep 6 (2016) 38572.

[10] Trujillo, M.; Alvarez, B.; Radi, R. One- and two-electron oxidation of thiols:

Mechanisms, kinetics and biological fates. Free Radic. Res. 50 (2016) 150-171.

[11] Gajewski, E.; Dizdaroglu, M.; Krutzsch, H. C.; Simic, M. G. Oh radical-induced crosslinks of methionine peptides. International Journal of Radiation Biology and Related Studies on Physical Chemistry and Medicine 46 (1984) 47-55. 
[12] Ronsein, G. E.; Winterbourn, C. C.; Di Mascio, P.; Kettle, A. J. Cross-linking methionine and amine residues with reactive halogen species. Free radical biology \& medicine 70 (2014) 278-287.

[13] Houee-Levin, C.; Bobrowski, K.; Horakova, L.; Karademir, B.; Schoneich, C.;

Davies, M. J.; Spickett, C. M. Exploring oxidative modifications of tyrosine: An update on mechanisms of formation, advances in analysis and biological consequences. Free Radic Res 49 (2015) 347-373.

[14] Medinas, D. B.; Gozzo, F. C.; Santos, L. F.; Iglesias, A. H.; Augusto, O. A

ditryptophan cross-link is responsible for the covalent dimerization of human superoxide dismutase 1 during its bicarbonate-dependent peroxidase activity. Free radical biology \& medicine 49 (2010) 1046-1053.

[15] Paviani, V.; Queiroz, R. F.; Marques, E. F.; Di Mascio, P.; Augusto, O. Production of lysozyme and lysozyme-superoxide dismutase dimers bound by a ditryptophan cross-link in carbonate radical-treated lysozyme. Free Radical Biology and Medicine 89 (2015) 72-82.

[16] Bhaskar, B.; Immoos, C. E.; Shimizu, H.; Sulc, F.; Farmer, P. J.; Poulos, T. L. A novel heme and peroxide-dependent tryptophan-tyrosine cross-link in a mutant of cytochrome c peroxidase. J Mol Biol 328 (2003) 157-166.

[17] Agon, V. V.; Bubb, W. A.; Wright, A.; Hawkins, C. L.; Davies, M. J. Sensitizermediated photooxidation of histidine residues: Evidence for the formation of reactive sidechain peroxides. Free Radic. Biol. Med. 40 (2006) 698-710.

[18] Shen, H.-R.; Spikes, J. D.; Smith, C. J.; Kopecek, J. Photodynamic cross-linking of proteins iv. Nature of the his-his bond(s) formed in the rose bengal-photosensitized crosslinking of $n$-benzoyl-1-histidine. J. Photochem. Photobiol. A: Chem. 130 (2000) 1-6. 
[19] Liu, M.; Zhang, Z.; Cheetham, J.; Ren, D.; Zhou, Z. S. Discovery and characterization of a photo-oxidative histidine-histidine cross-link in igg1 antibody utilizing (1)(8)o-labeling and mass spectrometry. Anal Chem 86 (2014) 4940-4948.

[20] Dizdaroglu, M.; Simic, M. G. Isolation and characterization of radiation-induced aliphatic peptide dimers. International Journal of Radiation Biology and Related Studies on Physical Chemistry and Medicine 44 (1983) 231-239.

[21] Davies, M. J.; Dean, R. T. Radical-mediated protein oxidation: From chemistry to medicine. Oxford: Oxford University Press; 1997.

[22] Dean, R. T.; Fu, S.; Stocker, R.; Davies, M. J. Biochemistry and pathology of radicalmediated protein oxidation. Biochem. J. 324 (1997) 1-18.

[23] Davies, K. J.; Lin, S. W.; Pacifici, R. E. Protein damage and degradation by oxygen radicals. Iv. Degradation of denatured protein. Journal of Biological Chemistry 262 (1987) 9914-9920.

[24] Chondrogianni, N.; Petropoulos, I.; Grimm, S.; Georgila, K.; Catalgol, B.; Friguet, B.; Grune, T.; Gonos, E. S. Protein damage, repair and proteolysis. Mol Aspects Med 35 (2014) 1-71.

[25] Liu, M.; Zhang, Z.; Zang, T.; Spahr, C.; Cheetham, J.; Ren, D.; Zhou, Z. S. Discovery of undefined protein cross-linking chemistry: A comprehensive methodology utilizing 18olabeling and mass spectrometry. Anal Chem 85 (2013) 5900-5908.

[26] Szweda, L. I.; Stadtman, E. R. Iron-catalyzed oxidative modification of glucose-6phosphate dehydrogenase from leuconostoc mesenteroides. Structural and functional changes. Journal of Biological Chemistry 267 (1992) 3096-3100.

[27] Friguet, B.; Stadtman, E. R.; Szweda, L. I. Modification of glucose-6-phosphate dehydrogenase by 4-hydroxy-2-nonenal. Formation of cross-linked protein that inhibits the multicatalytic protease. Journal of Biological Chemistry 269 (1994) 21639-21643. 
[28] Yang, H. C.; Wu, Y. H.; Liu, H. Y.; Stern, A.; Chiu, D. T. What has passed is prolog: New cellular and physiological roles of g6pd. Free Radic Res 50 (2016) 1047-1064.

[29] Cappellini, M. D.; Fiorelli, G. Glucose-6-phosphate dehydrogenase deficiency. Lancet $371(2008) 64-74$.

[30] Mahmoud, A. A.; Nor El-Din, A. K. Glucose-6-phosphate dehydrogenase activity and protein oxidative modification in patients with type 2 diabetes mellitus. J Biomark 2013 (2013) 430813.

[31] Hecker, P. A.; Leopold, J. A.; Gupte, S. A.; Recchia, F. A.; Stanley, W. C. Impact of glucose-6-phosphate dehydrogenase deficiency on the pathophysiology of cardiovascular disease. Am J Physiol Heart Circ Physiol 304 (2013) H491-500.

[32] Hecker, P. A.; Lionetti, V.; Ribeiro, R. F., Jr.; Rastogi, S.; Brown, B. H.; O'Connell, K. A.; Cox, J. W.; Shekar, K. C.; Gamble, D. M.; Sabbah, H. N.; Leopold, J. A.; Gupte, S. A.; Recchia, F. A.; Stanley, W. C. Glucose 6-phosphate dehydrogenase deficiency increases redox stress and moderately accelerates the development of heart failure. Circ Heart Fail 6 (2013) 118-126.

[33] Arese, P.; Gallo, V.; Pantaleo, A.; Turrini, F. Life and death of glucose-6-phosphate dehydrogenase (G6PDH) deficient erythrocytes - role of redox stress and band 3 modifications. Transfus Med Hemother 39 (2012) 328-334.

[34] Pattison, D. I.; Rahmanto, A. S.; Davies, M. J. Photo-oxidation of proteins. Photochem Photobiol Sci 11 (2012) 38-53.

[35] Porter, N. A.; Wagner, C. R. Phospholipid autoxidation. Adv. in Free Radical Biology and Medicine 2 (1986) 283-323.

[36] Yin, H.; Porter, N. A. New insights regarding the autoxidation of polyunsaturated fatty acids. Antioxid Redox Signal 7 (2005) 170-184. 
[37] Arenas, A.; Vasquez, R.; Lopez-Alarcon, C.; Lissi, E.; Silva, E. Oxidative damage of lysozyme and human serum albumin and their mixtures: A comparison of photosensitized and peroxyl radical promoted processes. Protein J 30 (2011) 359-365.

[38] Wright, A.; Bubb, W. A.; Hawkins, C. L.; Davies, M. J. Singlet oxygen-mediated protein oxidation: Evidence for the formation of reactive side-chain peroxides on tyrosine residues. Photochem. Photobiol. 76 (2002) 35-46.

[39] Pitre, S. P.; McTiernan, C. D.; Vine, W.; DiPucchio, R.; Grenier, M.; Scaiano, J. C. Visible-light actinometry and intermittent illumination as convenient tools to study ru(bpy)3cl2 mediated photoredox transformations. Sci Rep 5 (2015) 16397.

[40] Arenas, A.; Lopez-Alarcon, C.; Kogan, M.; Lissi, E.; Davies, M. J.; Silva, E.

Chemical modification of lysozyme, glucose 6-phosphate dehydrogenase, and bovine eye lens proteins induced by peroxyl radicals: Role of oxidizable amino acid residues. Chem Res Toxicol 26 (2013) 67-77.

[41] Werber, J.; Wang, Y. J.; Milligan, M.; Li, X.; Ji, J. A. Analysis of 2,2'-azobis (2amidinopropane) dihydrochloride degradation and hydrolysis in aqueous solutions. J Pharm Sci 100 (2011) 3307-3315.

[42] Niki, E. Free radical initiators as source of water- or lipid-soluble peroxyl radicals. Methods in enzymology 186 (1990) 100-108.

[43] Candiano, G.; Bruschi, M.; Musante, L.; Santucci, L.; Ghiggeri, G. M.; Carnemolla, B.; Orecchia, P.; Zardi, L.; Righetti, P. G. Blue silver: A very sensitive colloidal coomassie g250 staining for proteome analysis. Electrophoresis 25 (2004) 1327-1333.

[44] Anderson, W. B.; Nordlie, R. C. Glucose dehydrogenase activity of yeast glucose 6phosphate dehydrogenase. I. Selective stimulation by bicarbonate, phosphate, and sulfate. Biochemistry 7 (1968) 1479-1485. 
[45] Hawkins, C. L.; Morgan, P. E.; Davies, M. J. Quantification of protein modification by oxidants. Free Radic. Biol. Med. 46 (2009) 965-988.

[46] Friedman, M.; Cuq, J. L. Chemistry, analysis, nutritional-value, and toxicology of tryptophan in food - a review. Journal of agricultural and food chemistry 36 (1988) 10791093.

[47] Mariotti, M.; Leinisch, F.; Oersnes-Leeming, D. J.; Svensson, B.; Davies, M. J.; Hägglund, P. Mass spectrometry-based identification of cross-linked peptides in proteins subjected to photo-oxidation and chemical oxidation. submitted (2017)

[48] Cox, J.; Mann, M. Maxquant enables high peptide identification rates, individualized p.P.B.-range mass accuracies and proteome-wide protein quantification. Nat Biotechnol 26 (2008) 1367-1372.

[49] Cox, J.; Neuhauser, N.; Michalski, A.; Scheltema, R. A.; Olsen, J. V.; Mann, M. Andromeda: A peptide search engine integrated into the maxquant environment. J Proteome Res 10 (2011) 1794-1805.

[50] Bachi, A.; Dalle-Donne, I.; Scaloni, A. Redox proteomics: Chemical principles, methodological approaches and biological/biomedical promises. Chem Rev 113 (2013) 596698.

[51] Rykær, M.; Svensson, B.; Henriksen, K.; Davies, M. J.; Hägglund, P. Unrestricted mass spectrometric data analysis for identification, localization and quantification of oxidative protein modifications Molecular and cellular proteomics submitted (2017)

[52] Koradi, R.; Billeter, M.; Wuthrich, K. Molmol: A program for display and analysis of macromolecular structures. J Mol Graph 14 (1996) 51-55, 29-32.

[53] Davies, M. J. Reactive species formed on proteins exposed to singlet oxygen.

Photochem. Photobiol. Sci. 3 (2004) 17-25. 
[54] Headlam, H. A.; Davies, M. J. Beta-scission of side-chain alkoxyl radicals on peptides and proteins results in the loss of side chains as aldehydes and ketones. Free Radic. Biol. Med. 32 (2002) 1171-1184.

[55] Headlam, H. A.; Mortimer, A.; Easton, C. J.; Davies, M. J. B-scission of c-3 (bcarbon) alkoxyl radicals on peptides and proteins: A novel pathway which results in the formation of a-carbon radicals and the loss of amino acid side chains. Chem. Res. Toxicol. 13 (2000) 1087-1095.

[56] Haywood, J.; Mozziconacci, O.; Allegre, K. M.; Kerwin, B. A.; Schöneich, C. Lightinduced conversion of trp to gly and gly hydroperoxide in igg1. Molec. Pharmac. 10 (2013) 1146-1150.

[57] Gracanin, M.; Hawkins, C. L.; Pattison, D. I.; Davies, M. J. Singlet oxygen-mediated amino acid and protein oxidation: Formation of tryptophan peroxides and decomposition products Free Radic. Biol. Med. 47 (2009) 92-102.

[58] Amici, A.; Levine, R. L.; Tsai, L.; Stadtman, E. R. Conversion of amino acid residues in proteins and amino acid homopolymers to carbonyl derivatives by metal-catalyzed oxidation reactions. J. Biol. Chem. 264 (1989) 3341-3346.

[59] Levine, R. L.; Wehr, N.; Williams, J. A.; Stadtman, E. R.; Shacter, E. Determination of carbonyl groups in oxidized proteins. Methods Mol. Biol. 99 (2000) 15-24.

[60] Redmond, R. W.; Gamlin, J. N. A compilation of singlet oxygen yields from biologically relevant molecules. Photochem Photobiol 70 (1999) 391-475.

[61] Alarcon, E.; Edwards, A. M.; Aspee, A.; Borsarelli, C. D.; Lissi, E. A. Photophysics and photochemistry of rose bengal bound to human serum albumin. Photochem Photobiol Sci 8 (2009) 933-943. 
[62] Silvester, J. A.; Timmins, G. S.; Davies, M. J. Protein hydroperoxides and carbonyl groups generated by porphyrin-induced photo-oxidation of bovine serum albumin. Arch. Biochem. Biophys. 350 (1998) 249-258.

[63] Silvester, J. A.; Timmins, G. S.; Davies, M. J. Photodynamically-generated bovine serum albumin radicals: Evidence for damage transfer and oxidation at cysteine and tryptophan residues. Free Radic. Biol. Med. 24 (1998) 754-766.

[64] Fuentes-Lemus, E.; Dorta, E.; Escobar, E.; Aspee, A.; Pino, E.; Abasq, M. L.;

Speisky, H.; Silva, E.; Lissi, E.; Davies, M. J.; Lopez-Alarcon, C. Oxidation of free, peptide and protein tryptophan residues mediated by aaph-derived free radicals: Role of alkoxyl and peroxyl radicals. Rsc Adv 6 (2016) 57948-57955.

[65] Wilkinson, F.; Helman, W. P.; Ross, A. B. Rate constants for the decay and reactions of the lowest electronically excited state of molecular oxygen in solution. An expanded and revised compilation. J. Phys. Chem. Ref. Data 24 (1995) 663-1021.

[66] Alfassi, Z., ed. Peroxyl radicals. Chichester: John Wiley and Sons; 1997.

[67] Jensen, R. L.; Arnbjerg, J.; Ogilby, P. R. Reaction of singlet oxygen with tryptophan in proteins: A pronounced effect of the local environment on the reaction rate. $\mathrm{J}$ Am Chem Soc 134 (2012) 9820-9826.

[68] Nakashima, H.; Nishikawa, K. Discrimination of intracellular and extracellular proteins using amino acid composition and residue-pair frequencies. J Mol Biol 238 (1994) 54-61.

[69] Spikes, J. D.; Shen, H. R.; Kopeckova, P.; Kopecek, J. Photodynamic crosslinking of proteins. Iii. Kinetics of the fmn- and rose bengal-sensitized photooxidation and intermolecular crosslinking of model tyrosine-containing $n-(2-$ hydroxypropyl)methacrylamide copolymers. Photochem. Photobiol. 70 (1999) 130-137. 
[70] Shen, H.; Spikes, J. D.; Smith, C. J.; Kopecek, J. Photodynamic cross-linking of proteins v. Nature of the tyrosine-tyrosine bonds formed in the fmn-sensitized intermolecular cross-linking of $n$-acetyl-1-tyrosine. J. Photochem. Photobiol. A: Chemistry 133 (2000) 115122.

[71] Wardman, P. Reduction potentials on one-electron couples involving free radicals in aqueous solution. J. Phys. Chem. Ref. Data 18 (1989) 1637-1755.

[72] Packer, J. E.; Mahood, J. S.; Willson, R. L.; Wolfenden, B. S. Reactions of the trichloromethylperoxy free radical (cl3coo) with tryptophan, tryptophanyl-tyrosine and lysozyme. International Journal of Radiation Biology and Related Studies on Physical Chemistry and Medicine 39 (1981) 135-141.

[73] Ronsein, G. E.; de Oliveira, M. C.; de Medeiros, M. H.; Di Mascio, P.

Characterization of $\mathrm{o}(2)((1) \operatorname{delta}(\mathrm{g}))$-derived oxidation products of tryptophan: A combination of tandem mass spectrometry analyses and isotopic labeling studies. J Am Soc Mass Spectrom 20 (2009) 188-197.

[74] Storkey, C.; Pattison, D. I.; Gaspard, D. S.; Hagestuen, E. D.; Davies, M. J. Mechanisms of degradation of the natural high-potency sweetener $(2 \mathrm{r}, 4 \mathrm{r})$-monatin in mock beverage solutions. Journal of agricultural and food chemistry 62 (2014) 3476-3487.

[75] DeFelippis, M. R.; Faraggi, M.; Klapper, M. H. Evidence for through-bond longrange electron transfer in peptides. J Am Chem Soc 112 (1990) 5640-5462.

[76] Faraggi, M.; Klapper, M. H. Intramolecular long-range electron transfer in the ahemoglobin subunit. J Am Chem Soc 110 (1988) 5753-5756.

[77] Prutz, W. A.; Land, E. J. Charge transfer in peptides. Pulse radiolysis investigation of one-electron reactions in dipeptides of tryptophan and tyrosine. Int J Radiat Biol 36 (1979) $513-520$. 
[78] Prutz, W. A.; Land, E. J.; Sloper, R. W. Charge transfer in peptides. Effects of temperature, peptide length and solvent conditions upon intramolecular one-electron reactions involving tryptophan and tyrosine. J. Chem. Soc., Faraday Trans. 177 (1981) 281292.

[79] Lewisch, S. A.; Levine, R. L. Determination of 2-oxohistidine by amino acid analysis. Anal Biochem 231 (1995) 440-446.

[80] Schoneich, C. Mechanisms of metal-catalyzed oxidation of histidine to 2-oxohistidine in peptides and proteins. J Pharm Biomed Anal 21 (2000) 1093-1097.

[81] Tomita, M.; Irie, M.; Ukita, T. Sensitized photooxidation of histidine and its derivatives. Products and mechanism of the reaction. Biochemistry 8 (1969) 5149-5160.

[82] Sysak, P. K.; Foote, C. S.; Ching, T.-Y. Chemistry of singlet oxygen - xxv. Photooxygenation of methionine. Photochem. Photobiol. 26 (1977) 19-27.

[83] Barata-Vallejo, S.; Ferreri, C.; Zhang, T.; Permentier, H.; Bischoff, R.; Bobrowski, K.; Chatgilialoglu, C. Radiation chemical studies of gly-met-gly in aqueous solution. Free Radic Res 50 (2016) S24-S39.

[84] Schoneich, C.; Aced, A.; Asmus, K. D. Mechanism of oxidation of aliphatic thioethers to sulfoxides by hydroxyl radicals - the importance of molecular oxygen. J Am Chem Soc 115 (1993) 11376-11383.

[85] Schoneich, C. Methionine oxidation by reactive oxygen species: Reaction mechanisms and relevance to alzheimer's disease. Biochim. Biophys. Acta 1703 (2005) 111119.

[86] Ma, Y. S.; Chao, C. C.; Stadtman, E. R. Oxidative modification of glutamine synthetase by 2,2'-azobis(2- amidinopropane) dihydrochloride. Arch Biochem Biophys 363 (1999) 129-134. 
[87] Vought, V.; Ciccone, T.; Davino, M. H.; Fairbairn, L.; Lin, Y.; Cosgrove, M. S.; Adams, M. J.; Levy, H. R. Delineation of the roles of amino acids involved in the catalytic functions of leuconostoc mesenteroides glucose 6-phosphate dehydrogenase. Biochemistry 39 (2000) 15012-15021.

[88] Leitner, A.; Joachimiak, L. A.; Unverdorben, P.; Walzthoeni, T.; Frydman, J.; Forster, F.; Aebersold, R. Chemical cross-linking/mass spectrometry targeting acidic residues in proteins and protein complexes. Proc Natl Acad Sci U S A 111 (2014) 9455-9460.

[89] Cosgrove, M. S.; Gover, S.; Naylor, C. E.; Vandeputte-Rutten, L.; Adams, M. J.;

Levy, H. R. An examination of the role of asp-177 in the his-asp catalytic dyad of leuconostoc mesenteroides glucose 6-phosphate dehydrogenase: X-ray structure and ph dependence of kinetic parameters of the d177n mutant enzyme. Biochemistry 39 (2000) 15002-15011.

[90] Naylor, C. E.; Gover, S.; Basak, A. K.; Cosgrove, M. S.; Levy, H. R.; Adams, M. J. $\mathrm{Nadp}+$ and nad + binding to the dual coenzyme specific enzyme leuconostoc mesenteroides glucose 6-phosphate dehydrogenase: Different interdomain hinge angles are seen in different binary and ternary complexes. Acta Crystallogr D Biol Crystallogr 57 (2001) 635-648.

[91] Cosgrove, M. S.; Naylor, C.; Paludan, S.; Adams, M. J.; Levy, H. R. On the mechanism of the reaction catalyzed by glucose 6-phosphate dehydrogenase. Biochemistry 37 (1998) 2759-2767.

[92] Szweda, L. I.; Stadtman, E. R. Oxidative modification of glucose-6-phosphate dehydrogenase from leuconostoc mesenteroides by an iron(ii)-citrate complex. Arch Biochem Biophys 301 (1993) 391-395.

[93] Lissi, E. A.; Clavero, N. Inactivation of lysozyme by alkylperoxyl radicals. Free Radic. Res. Comm. 10 (1990) 177-184. 


\section{Figures and legends}

Fig. 1. Oxidation of G6PDH ( $30 \mu \mathrm{M}$, in $10 \mathrm{mM}$ phosphate buffer, $\mathrm{pH}$ 7.4) by ${ }^{1} \mathrm{O}_{2}$ and $\mathrm{ROO} \bullet$ affects the protein's structural integrity (panel A), modifies individual amino acids (panel B) and decreases enzymatic activity (panel C). ${ }^{1} \mathrm{O}_{2}$ was generated via photo-oxidation $(10 \mu \mathrm{M}$ Rose Bengal, visible light, $\mathrm{O}_{2}$ in $70 \% \mathrm{D}_{2} \mathrm{O}, 90 \mathrm{~min}$ ), and $\mathrm{ROO}{ }^{\bullet}$ by thermal degradation of AAPH $\left(10 \mathrm{mM}, 40^{\circ} \mathrm{C}, 90 \mathrm{~min}\right)$. Panel A: SDS-PAGE of G6PDH run under reducing conditions on $4-12 \%$ Bis-Tris acrylamide gels with $60 \mu \mathrm{g}$ protein/well. $\mathrm{M}=$ molecular mass markers, with masses indicated on left hand vertical axis. Panel B: As panel A, but with subsequent Western blotting and use of anti-dityrosine (left hand image) and anti-NFK (right hand image) antibodies; for further details, see Materials and Methods and main text. Panel C: Enzymatic activity of control and oxidized G6PDH exposed to AAPH and photo-oxidation as indicated above.

Fig. 2. Protein oxidation results in selective damage to amino acids within the protein sequence, as shown by MS analysis. G6PDH (30 $\mu \mathrm{M}, 10 \mathrm{mM}$ phosphate buffer, $\mathrm{pH}$ 7.4) was oxidized with ${ }^{1} \mathrm{O}_{2}\left(10 \mu \mathrm{M}\right.$ Rose Bengal, visible light, $\mathrm{O}_{2}$ in $\left.70 \% \mathrm{D}_{2} \mathrm{O}, 90 \mathrm{~min}\right)$, or $\mathrm{ROO}{ }^{\bullet}$ from AAPH (10 mM, $\left.40^{\circ} \mathrm{C}, 90 \mathrm{~min}\right)$. Panel (A): Sequence coverage of G6PDH detected after exposure to photo-oxidation (top) or $\mathrm{ROO}^{\bullet}$ (bottom); grey: non-covered sequence, blue: sequences involved in cross-linking. A list of all identified peptides is provided in Supplementary Tables 3 and 4. Panel (B): Mapping of oxidative changes detected at individual amino acids by MS in the G6PDH protein sequence after exposure to (a) ${ }^{1} \mathrm{O}_{2}$ and (b) $\mathrm{ROO}^{\bullet}$. Vertical axis indicates the $\%$ modification (with a cut-off of $>0.3 \%$ ) of the amino acid at specific sites, calculated as outlined in Materials and methods from technical 
replicates, with the horizontal axis indicating the amino acid sequence and numbering. The position of the catalytic dyad and residues involved in NADP and G6P binding are indicated. Panel (A)

Fig. 3. Trp, His, Met and Tyr residues in G6PDH are readily oxidized. Analysis of G6PDH (30 $\mu \mathrm{M}, 10 \mathrm{mM}$ phosphate buffer, $\mathrm{pH}$ 7.4) amino acid composition by mass spectrometry (black bars) or UPLC with fluorescence detection (grey bars) after exposure of the protein to (Panel A) photo-oxidation (10 $\mu \mathrm{M}$ Rose Bengal, visible light, $\mathrm{O}_{2}$ in $70 \% \mathrm{D}_{2} \mathrm{O}, 90 \mathrm{~min}$ ), or (Panel B) $\mathrm{ROO}^{\bullet}$ from AAPH $\left(10 \mathrm{mM}, 40^{\circ} \mathrm{C}, 90 \mathrm{~min}\right)$. For further details, see text and Materials and Methods. Data are mean + SD from three independent experiments: amino acid levels have been normalized to the concentration of Ala residues to compensate for any loss of materials during processing. * As the acid hydrolysis method converts Q to E (Gln to Glu) and $\mathrm{N}$ to $\mathrm{D}$ (Asn to Asp) the totals of these are used.

Fig. 4. Quantification of parent and oxidized products of Trp (Panel A), and Tyr and Phe (Panel B) detected by MS and UPLC with fluorescence detection (LC/FL) on treatment of G6PDH (30 $\mu \mathrm{M}, 10 \mathrm{mM}$ phosphate buffer, $\mathrm{pH}$ 7.4) to ${ }^{1} \mathrm{O}_{2}$ (photo-oxidation using $10 \mu \mathrm{M}$ Rose Bengal, visible light, $\mathrm{O}_{2}$ in $70 \% \mathrm{D}_{2} \mathrm{O}, 90 \mathrm{~min}$ ), or $\mathrm{ROO}{ }^{\bullet}$ (incubation with $10 \mathrm{mM}$ $\left.\mathrm{AAPH}, 40{ }^{\circ} \mathrm{C}, 90 \mathrm{~min}\right)$. In panel $\mathrm{A}$, the data are presented as \% values of the initial composition of the specific amino acids in G6PDH for the ${ }^{1} \mathrm{O}_{2}$ (left pair of bars) and $\mathrm{ROO}^{\bullet}$ (right pair of bars) systems. The data arising from the UPLC analyses are presented as specific species (parent Trp, NFK/Kyn and unknown), whereas the MS data are presented as average mass shifts, due to the absence of specific data on the nature of these species. The $m / z+0$, indicates unmodified parent Trp; the $m / z+4$ are likely to be due to Kyn, the $m / z+14$ $($ accurately +13.98$)$ due to carbonyl formation, the $m / z+16$ due to the addition of a single 
oxygen atom (hydroxylation), the $m / z+32$ due to the addition of 2 oxygen atoms (NFK, hydroperoxides or diols) and the $m / z+48$ due to the addition of 3 oxygen atoms. In panel B, data are presented for the levels of specific Tyr and Phe oxidation products detected by UPLC with fluorescence detection (LC/FL) for the experimental conditions indicated, with $o$ and $m$-Tyr being oxidation products of Phe, and DOPA and di-Tyr being oxidation products of Tyr.

Fig. 5. Selectivity of damage to specific Trp residues in G6DPH induced by ${ }^{1} \mathrm{O}_{2}$ (panel A) or $\mathrm{ROO}^{\bullet}$ (panel B). Oxidations were carried out as described in the legend to Figs. 1 and 4 then analyzed by MS for modifications at specific Trp residues. The data are presented as the relative proportions of the total Trp present in the parent proteins, with these expressed as $100 \%$. For the ${ }^{1} \mathrm{O}_{2}$ system (panel A), W248, W434 and W441 were not detected on the relevant peptide (see Fig. 2) despite a high degree of sequence coverage (see text). Likely assignments of mass changes are given in the legend to Fig. 4.

Fig. 6. Identification of cross-linked peptides in $\mathrm{G} 6 \mathrm{PDH}(30 \mu \mathrm{M}$ in $10 \mathrm{mM}$ phosphate buffer, pH 7.4) exposed to ${ }^{1} \mathrm{O}_{2}\left(10 \mu \mathrm{M}\right.$ Rose Bengal, visible light, $\mathrm{O}_{2}$ in $\left.70 \% \mathrm{D}_{2} \mathrm{O}, 90 \mathrm{~min}\right)$, or $\mathrm{ROO}{ }^{\bullet}$ from AAPH (10 mM, $\left.40{ }^{\circ} \mathrm{C}, 90 \mathrm{~min}\right)$ by targeted $\mathrm{MS} / \mathrm{MS}$ high-energy collisional dissociation analysis. Panel A: assignment of MS/MS spectra of the cross-linked peptide (FVDAISAVYTADK) (APLETYK) indicating ions assigned to the two peptides sequences cross-linked by a Tyr-Tyr bond. Panel B: assignment of MS/MS spectra of the cross-linked peptide (DYIK) (FGNPIFDAAWNK) indicating ions assigned to the two peptides sequences cross-linked by a Tyr-Trp bond. For further details see text. 
Fig. 7. Localization of the Trp residues and their relative susceptibility to oxidation as judged by consumption of the parent Trp residue. Samples were prepared and analyzed as described in the legend to Fig. 5, with the extent of modification to the specific Trp residues induced by ${ }^{1} \mathrm{O}_{2}$ (left panel) and $\mathrm{ROO}^{\bullet}$ (right panel) mapped on to the protein and visualized on the G6PDH 3D structure (from PDB sequence: 1DPG). The extent of oxidation of specific Trp residues, is indicated by increasing red coloration. For the photo-oxidation system two of the Trp residues was not detected after oxidation; these two Trp residues are coloured light blue. With both oxidants, Trp 402 was found to be the most succeptible to oxidation and also displays the greatest solvent/surface olouration. Trp248, which was not significantly modified with either oxidant system is located deep within the accessibility as indicated by bright cprotein core and has no significant surface accessibility.

Fig. 8. Localization of Tyr and Trp residues detected in cross-linked peptides from oxidized G6PDH. For all pairs of residues, at least one of the residues is determined surface-accessible as indicated by brightly colored regions of the structures. The pairs of residues Trp $203-$ Tyr 207 and Tyr 276 - Tyr 284, which were detected as cross-linked species following photooxidation were determined to be in close contact, consistent with intramolecular cross-linking of these residue pairs. The other pairs are located within 12 - $16 \AA$ distance of the partner residue and may form either inter- or intra-molecular cross-links. For further details, see text. Red colored atoms: oxygen; blue atoms: nitrogen; yellow/ orange atoms: carbon atoms of Tyr side-chain; green atoms: carbon atoms of Trp side-chain. 


\section{Highlights}

- Glucose-6-phosphate dehydrogenase (G6PDH), a key pentose phosphate pathway enzyme, maintains cellular NADPH levels

- Decreased G6PDH activity is a common genetic mutation and associated with enhanced oxidative stress

- G6PDH oxidation by singlet oxygen and peroxyl radicals results in a loss of enzyme activity

- Trp, His, Tyr and Met are major targets for both oxidants and give rise to multiple products

- Trp and Tyr modifications and formation of Tyr-Tyr and Tyr-Trp cross-links have been mapped by MS 


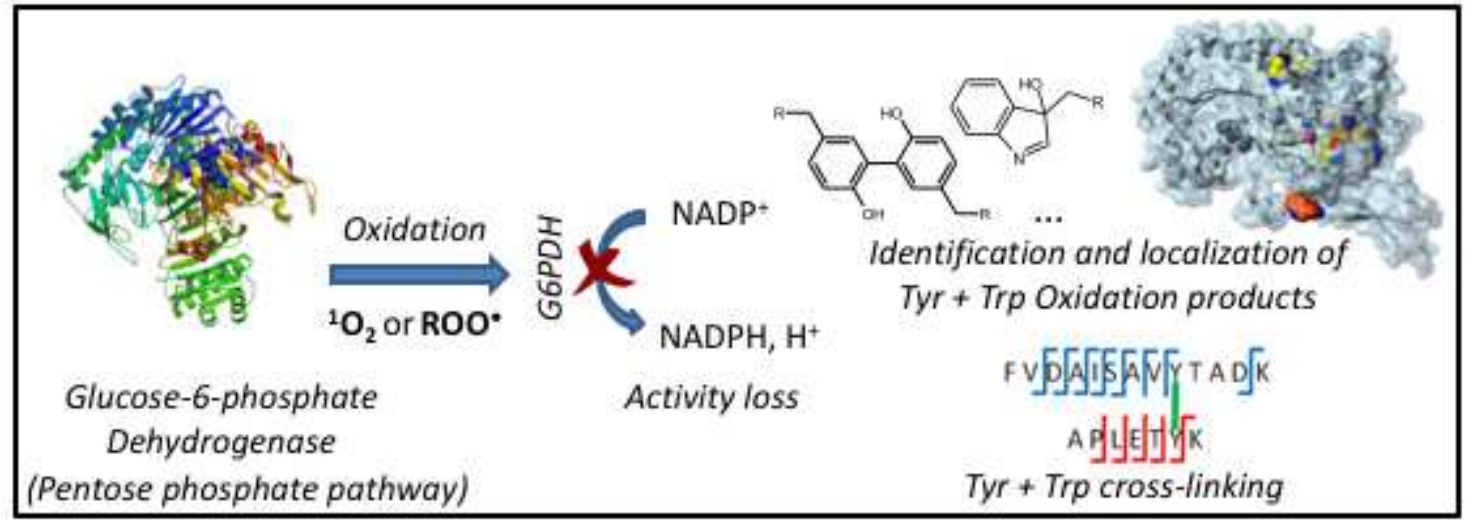

\section{Graphical abstract}




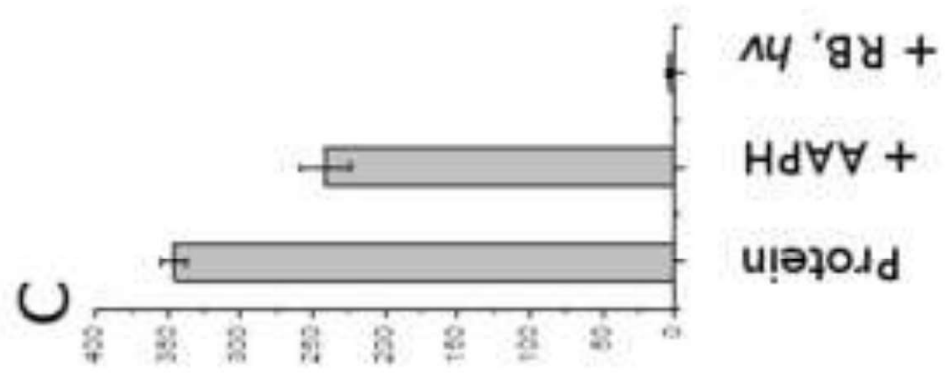

ธะ/ เพแก
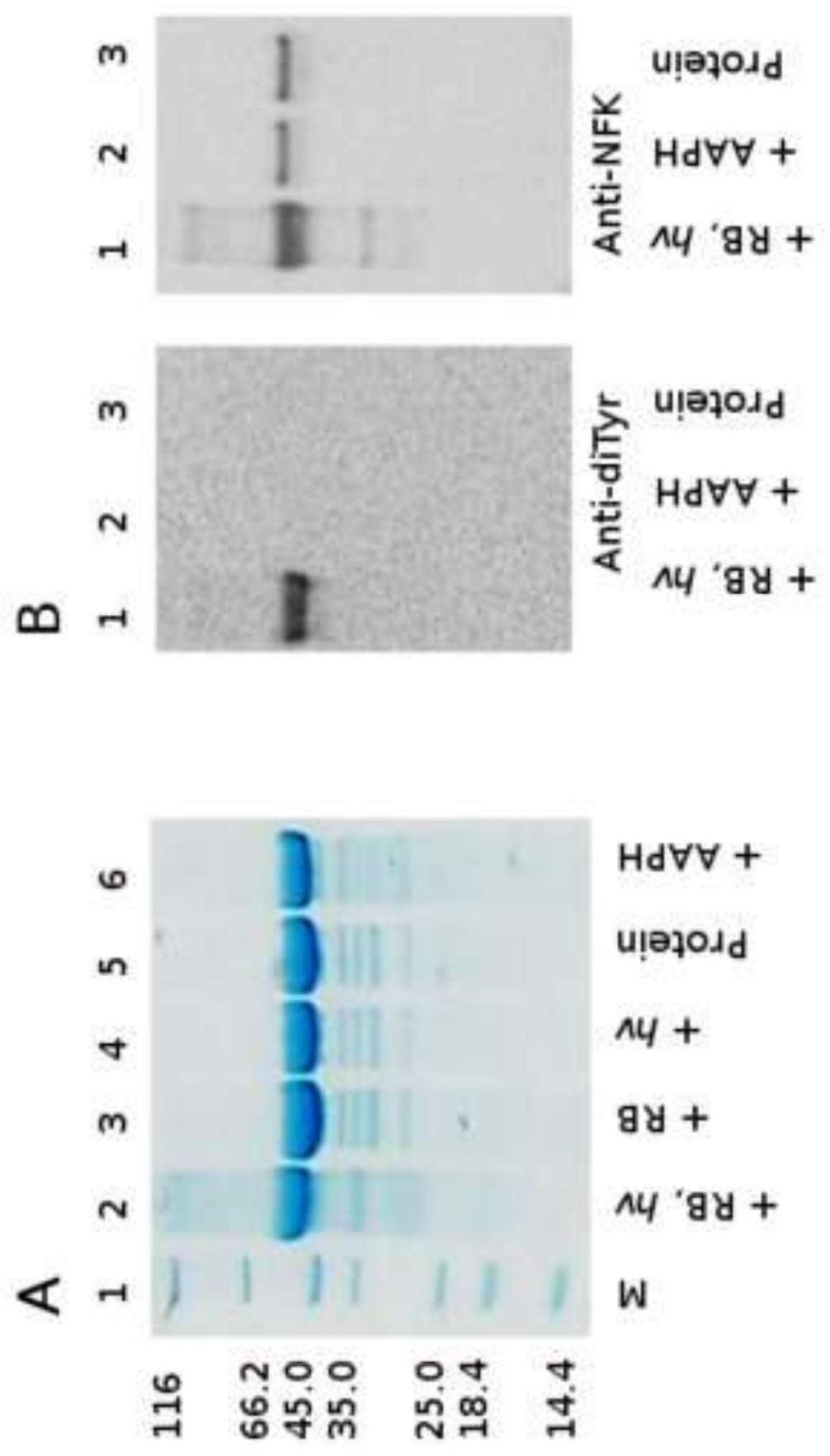


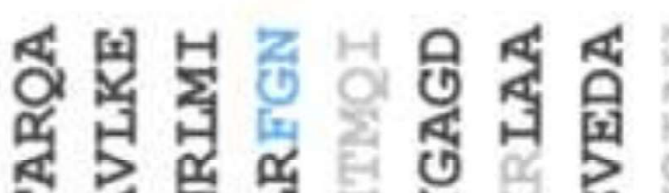

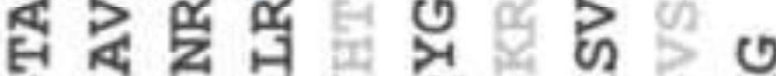

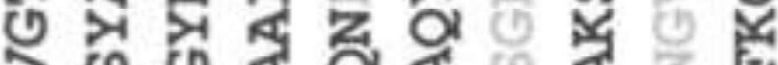

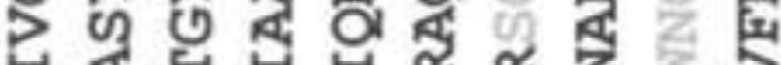

为

I 9 \&

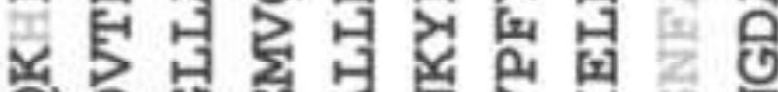

Q 20 至

-1
पू

(1) 4 自

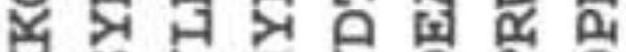

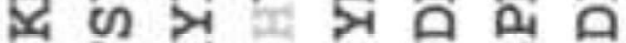

본

Z

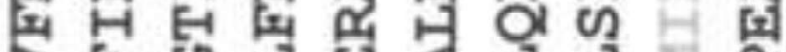

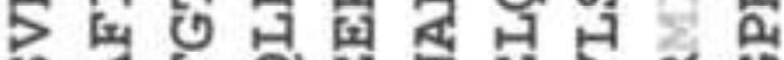

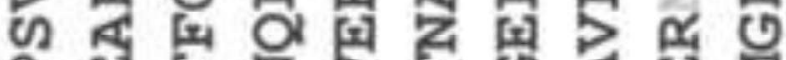

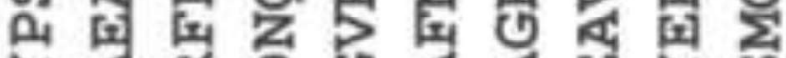

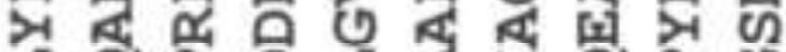

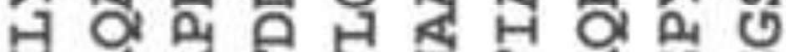

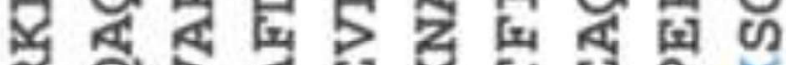

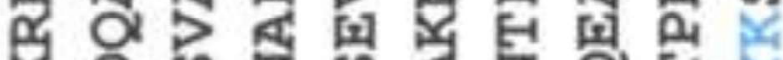

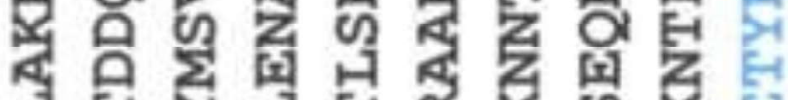

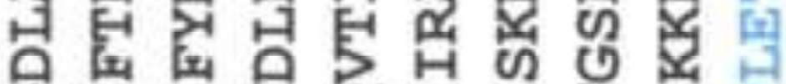

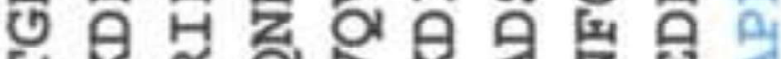

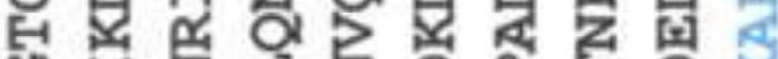

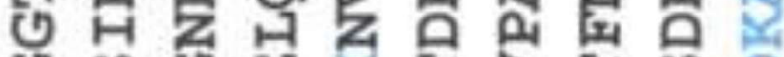

क ल

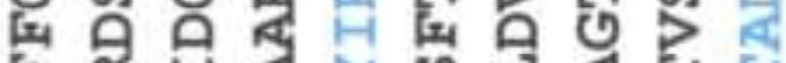

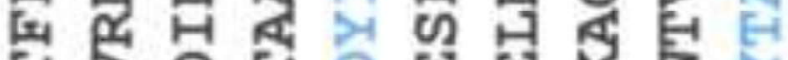

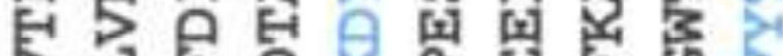

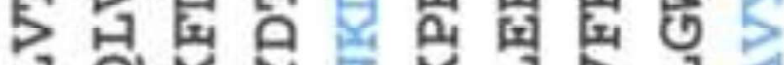

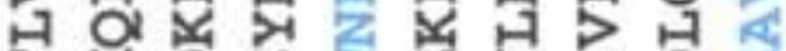

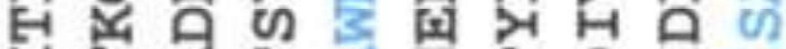

乎 H

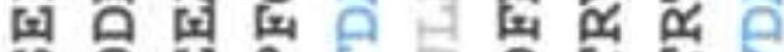

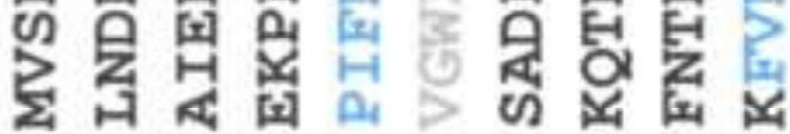

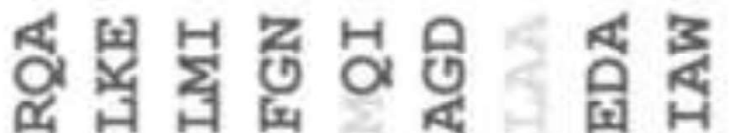

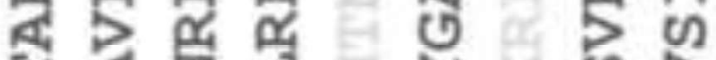

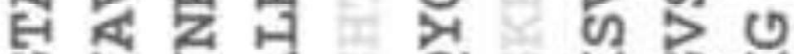

(1)

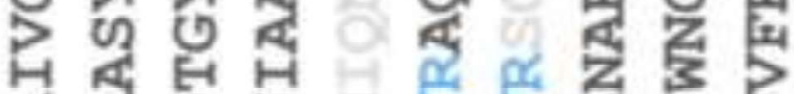

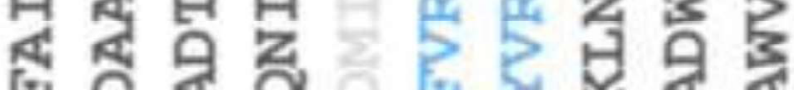

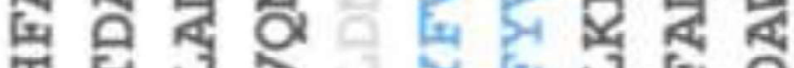

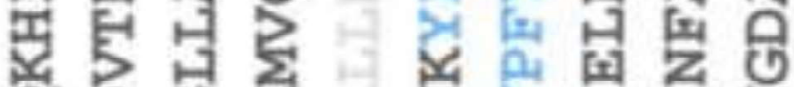

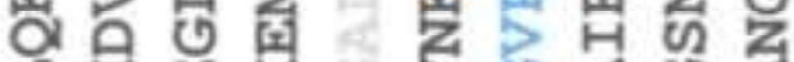

H曹

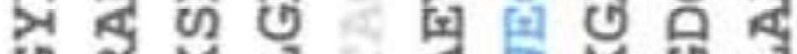

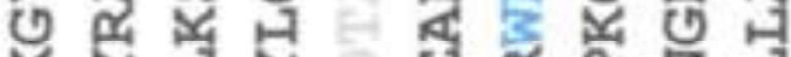

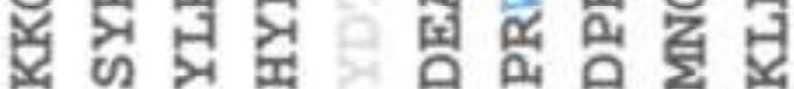

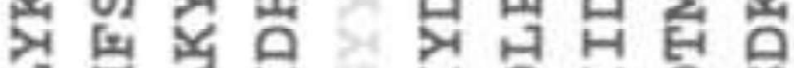

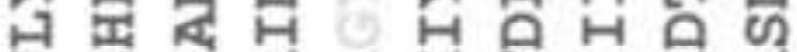

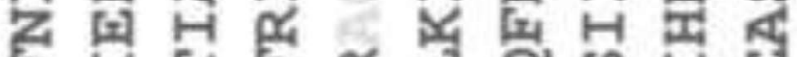

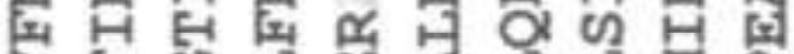

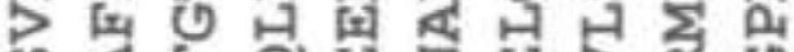

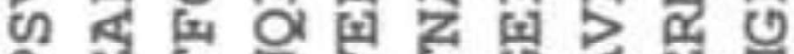

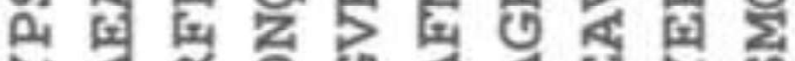

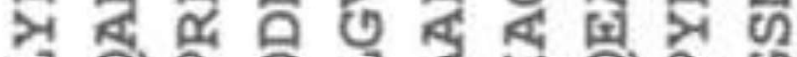

$\theta$ O म $\mathrm{A}$ स $\mathrm{O}$ O

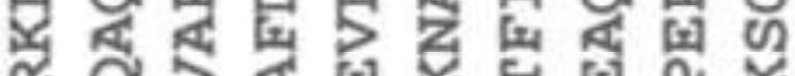

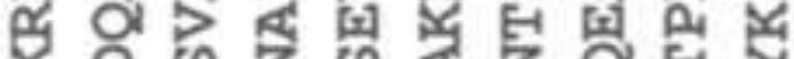

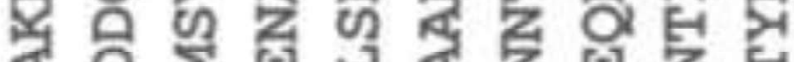

द $Q$ ¿ ब

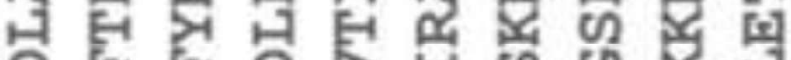

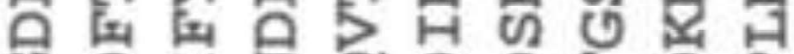

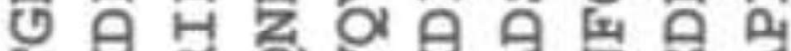

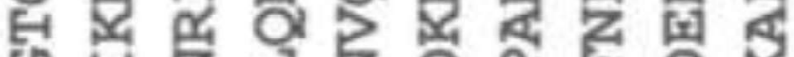

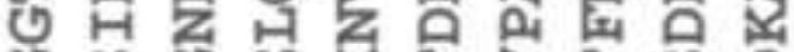

( )

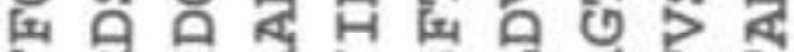

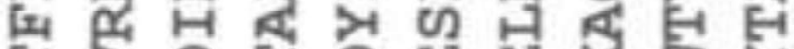

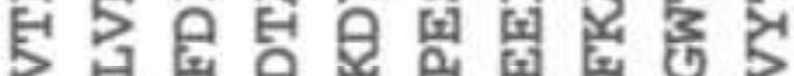

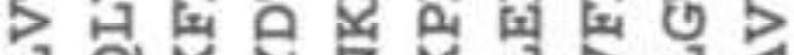

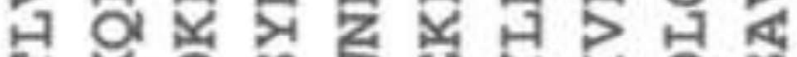

E 0 \%

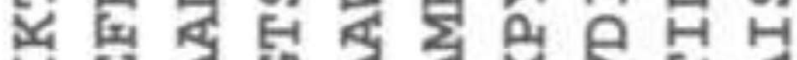

H

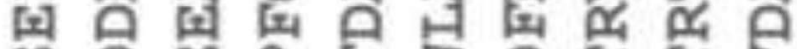

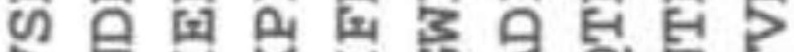

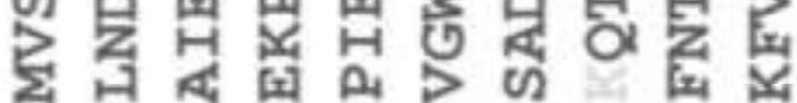




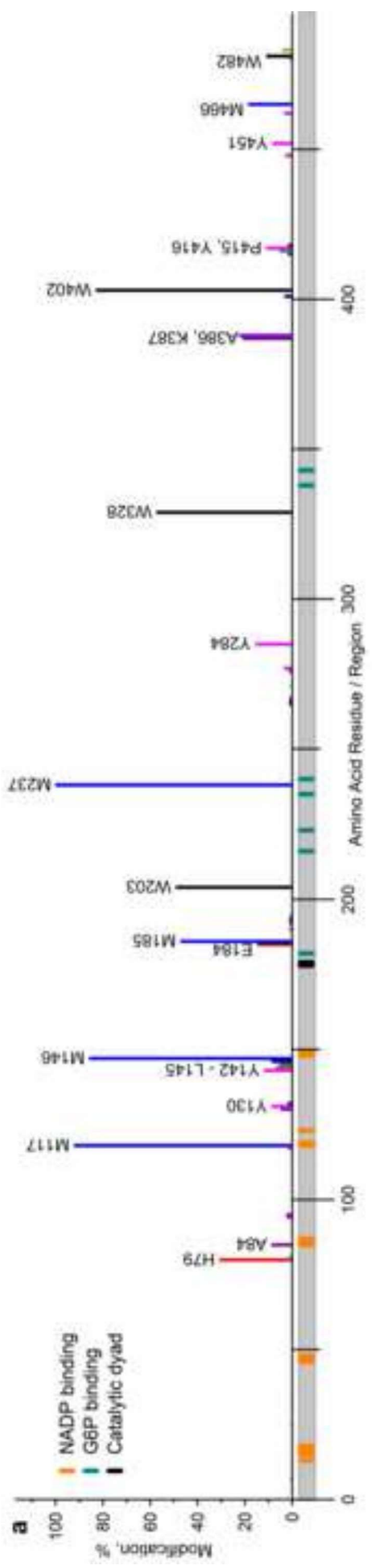




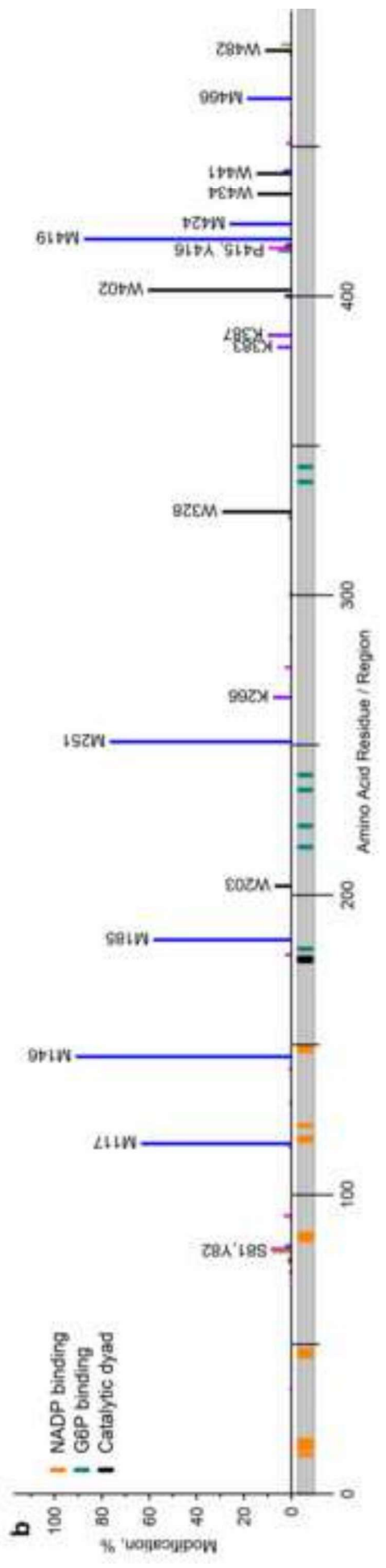

온 


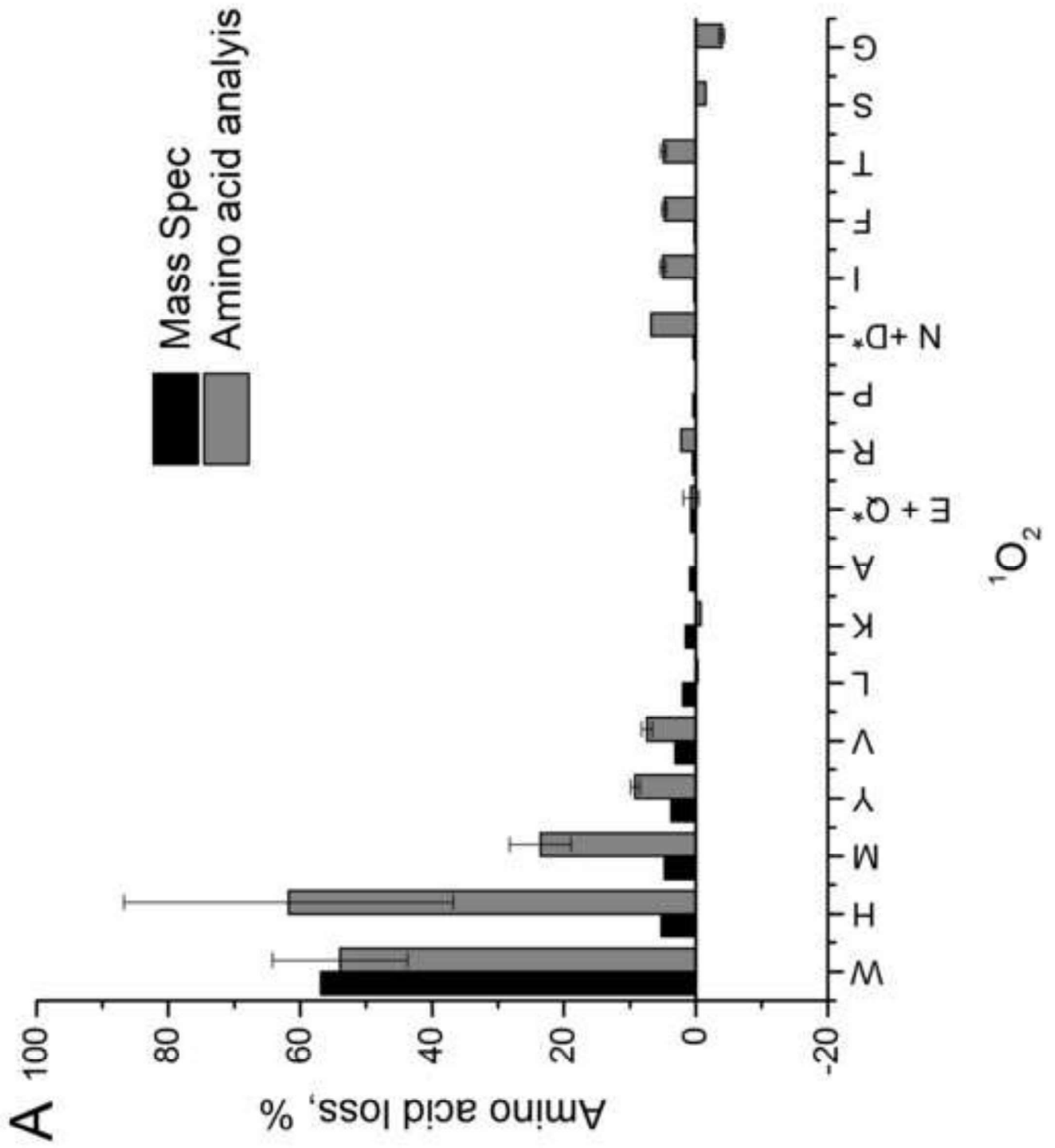




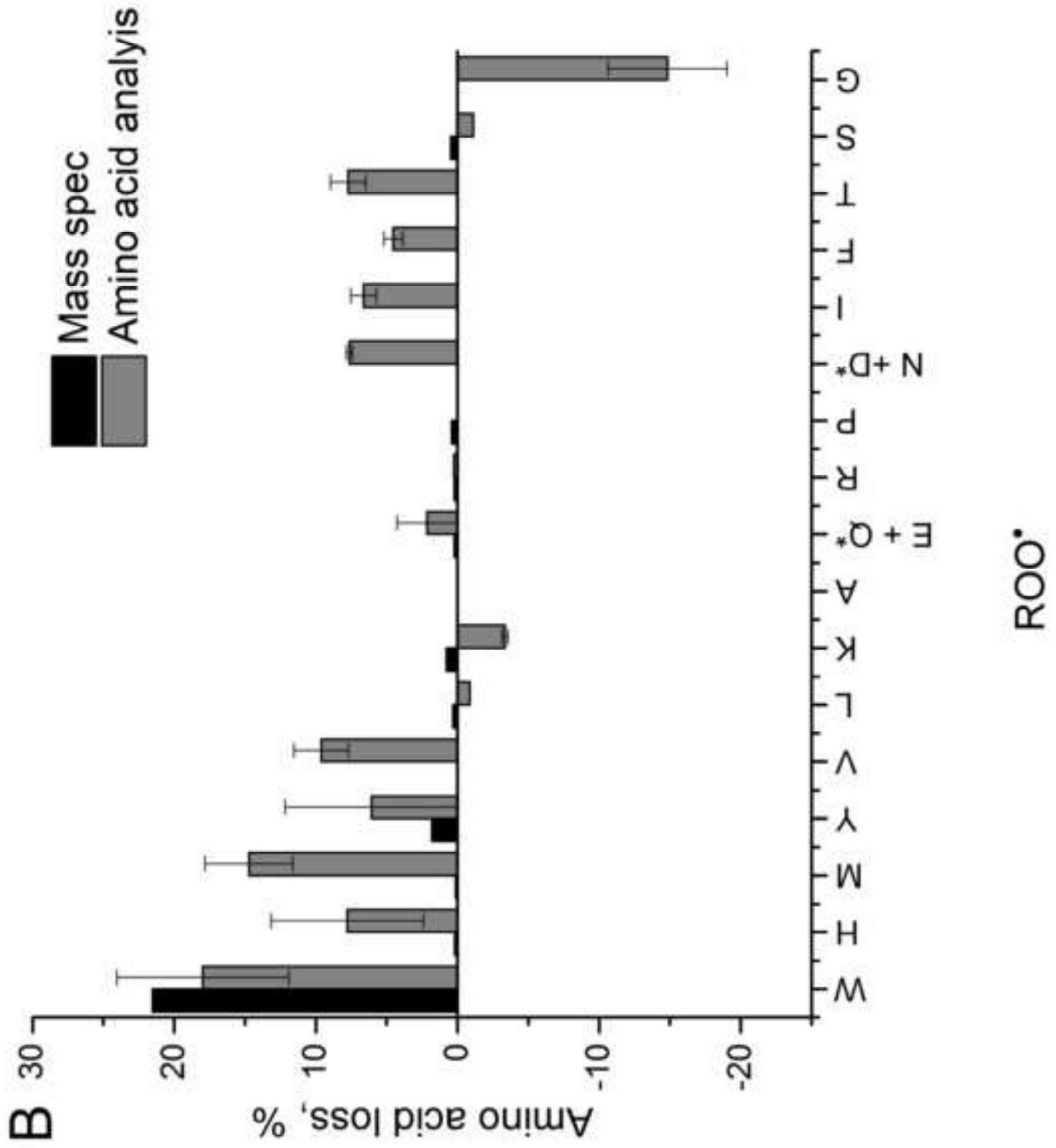



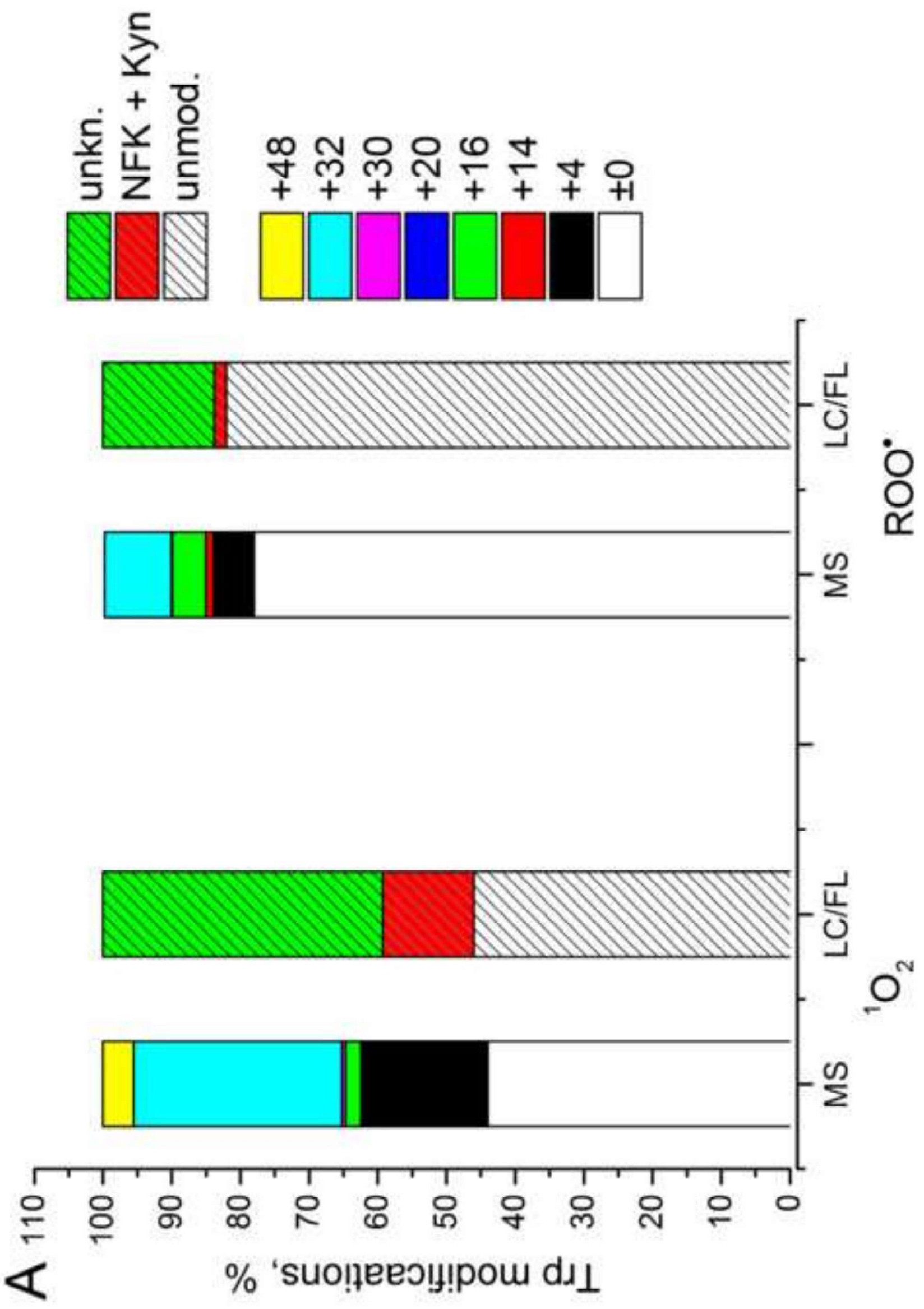


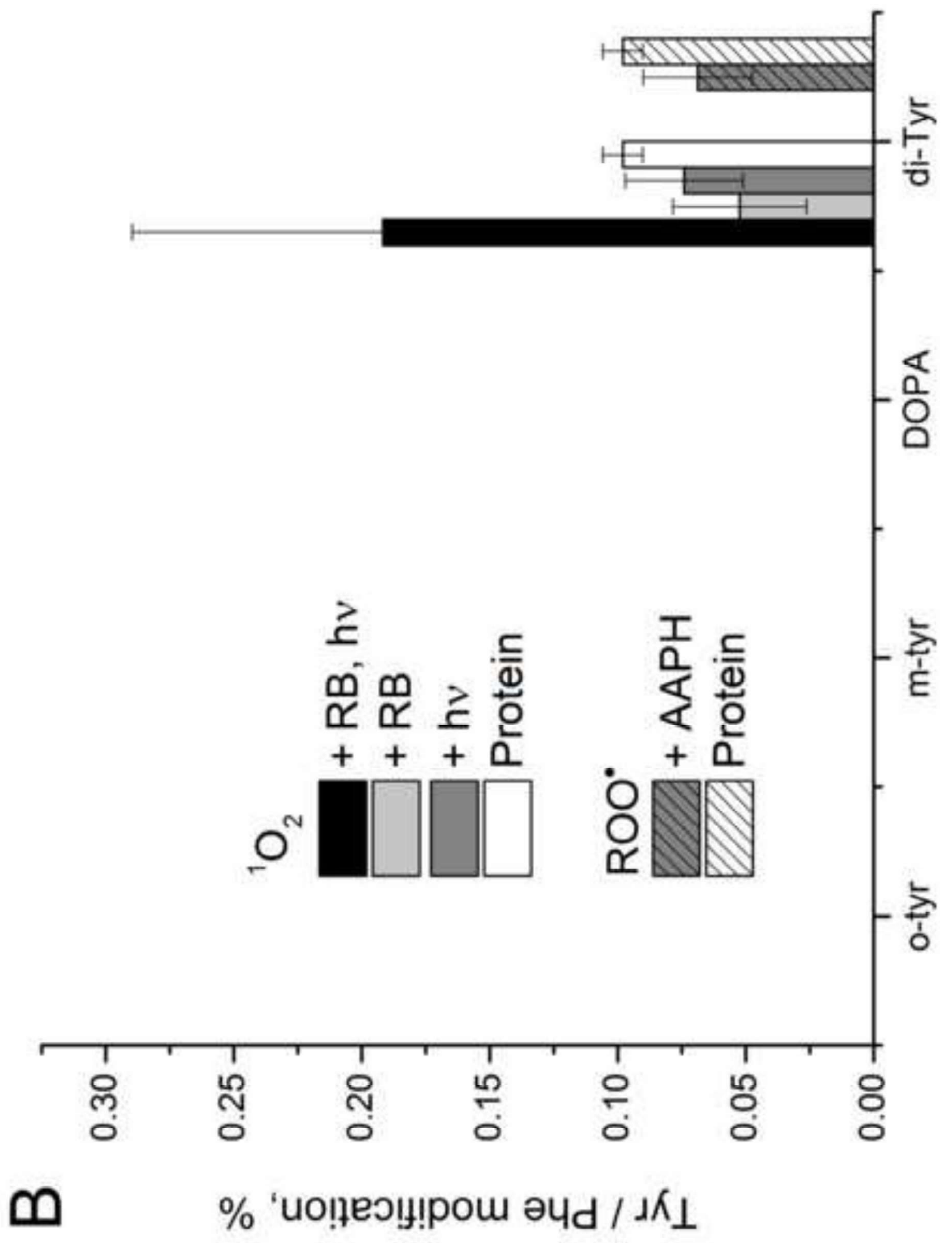




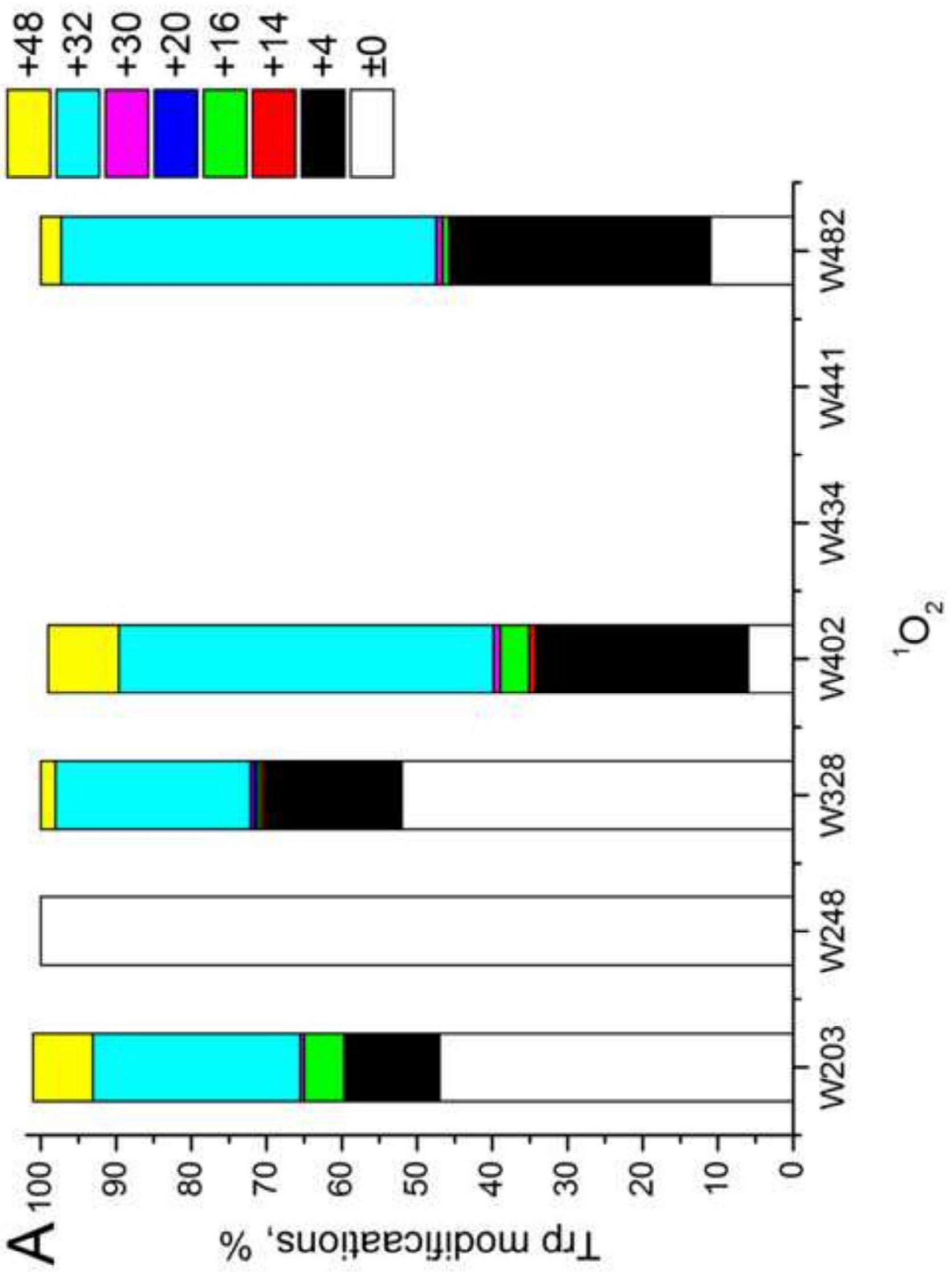




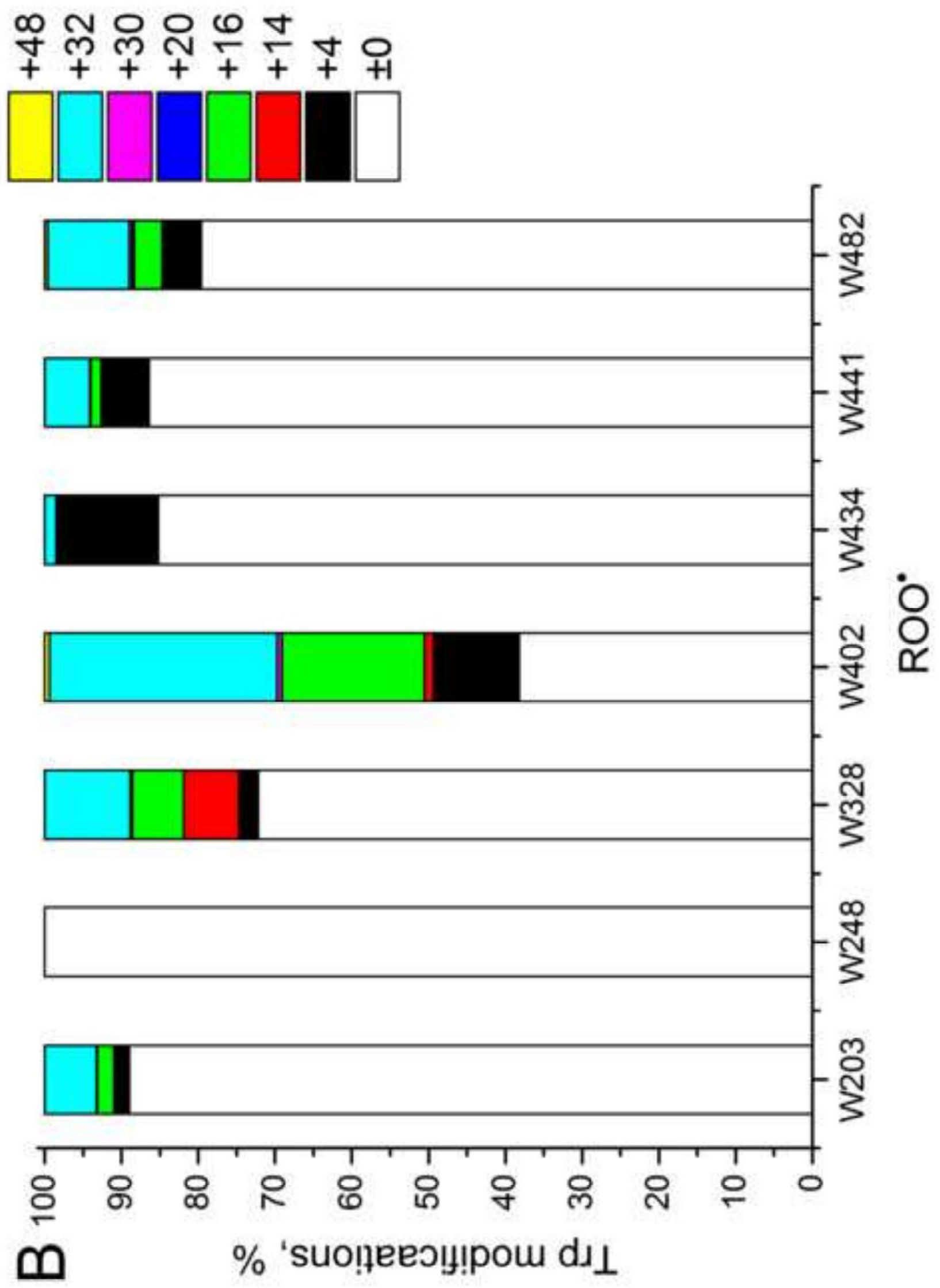




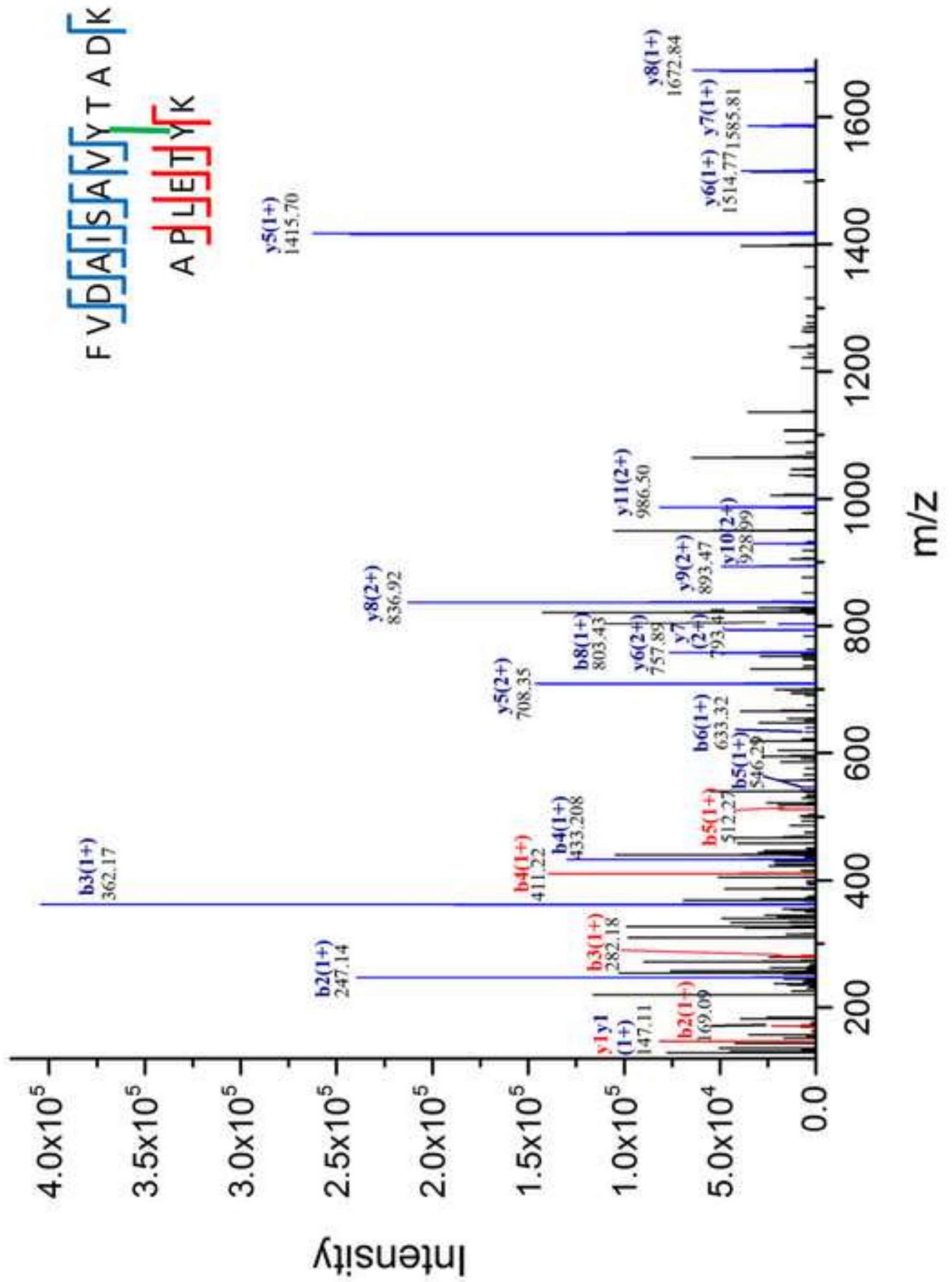



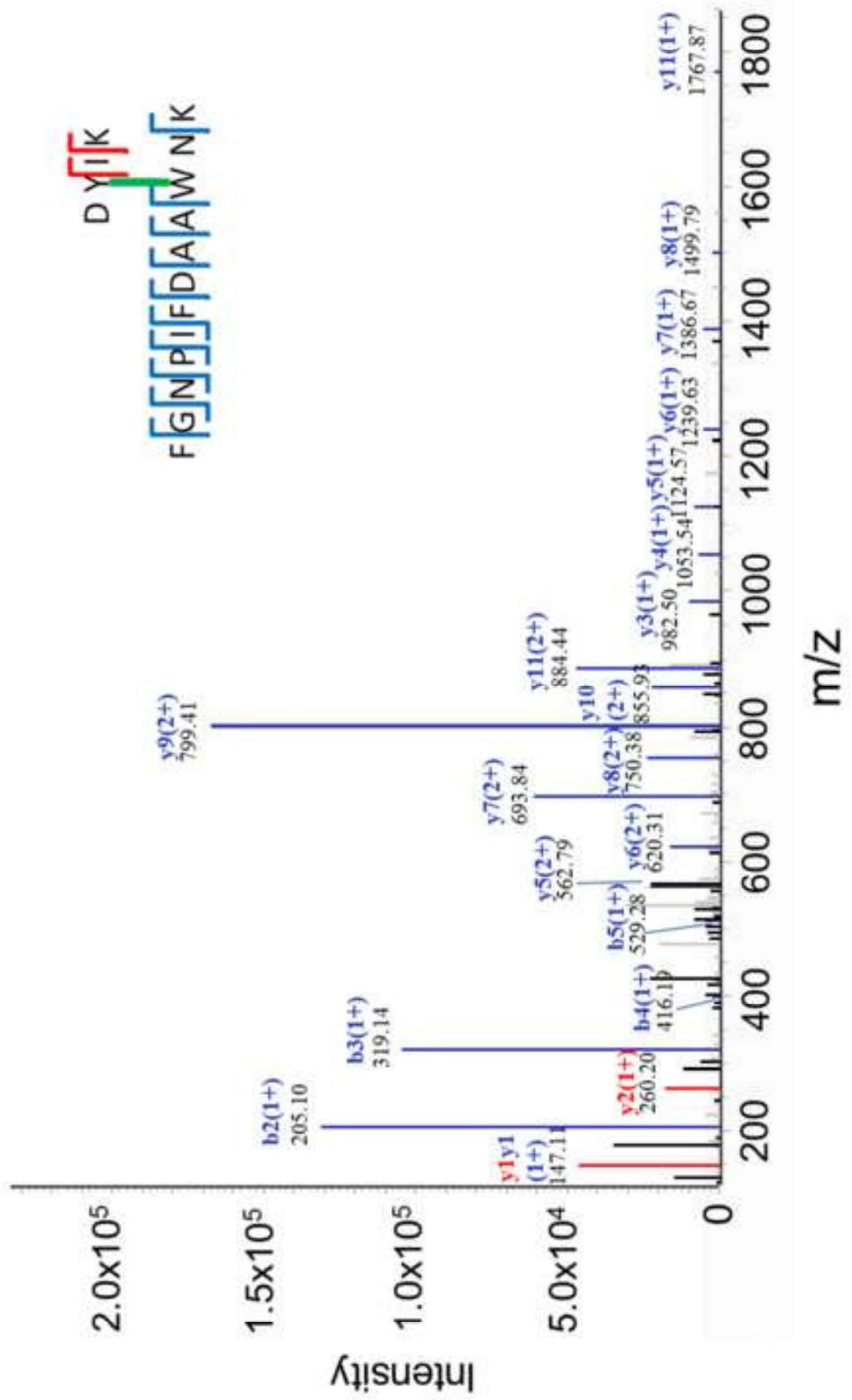

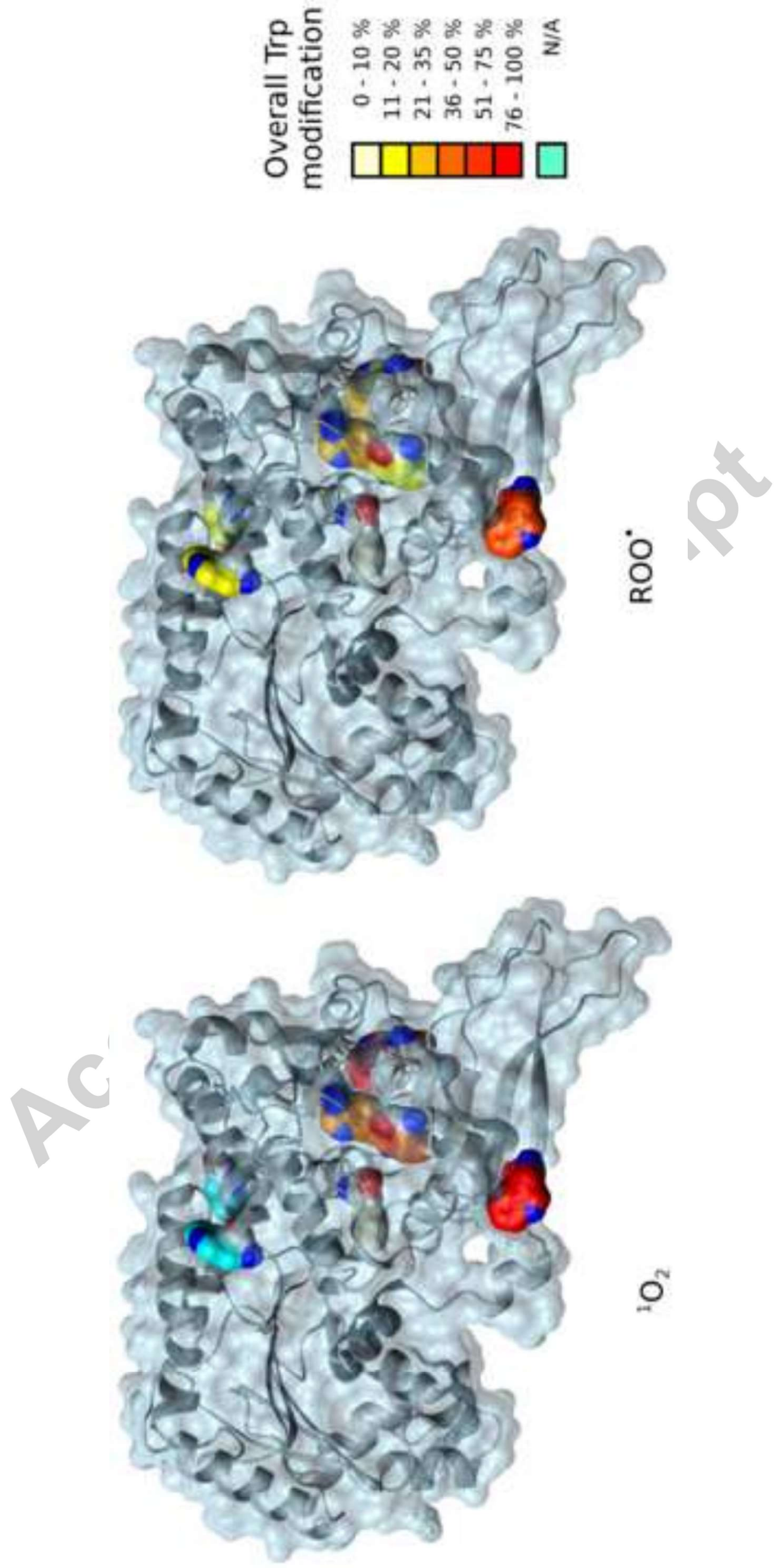


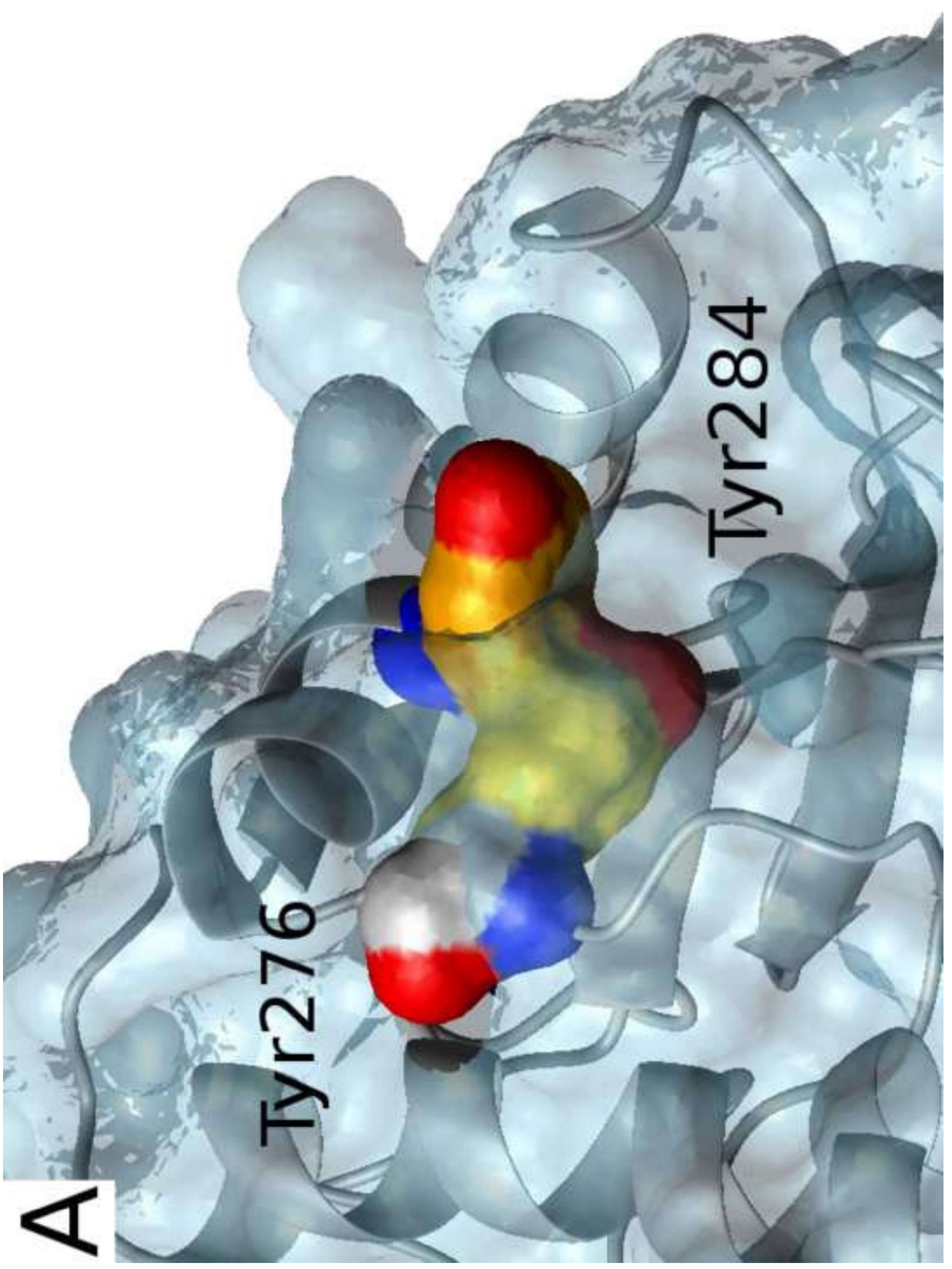




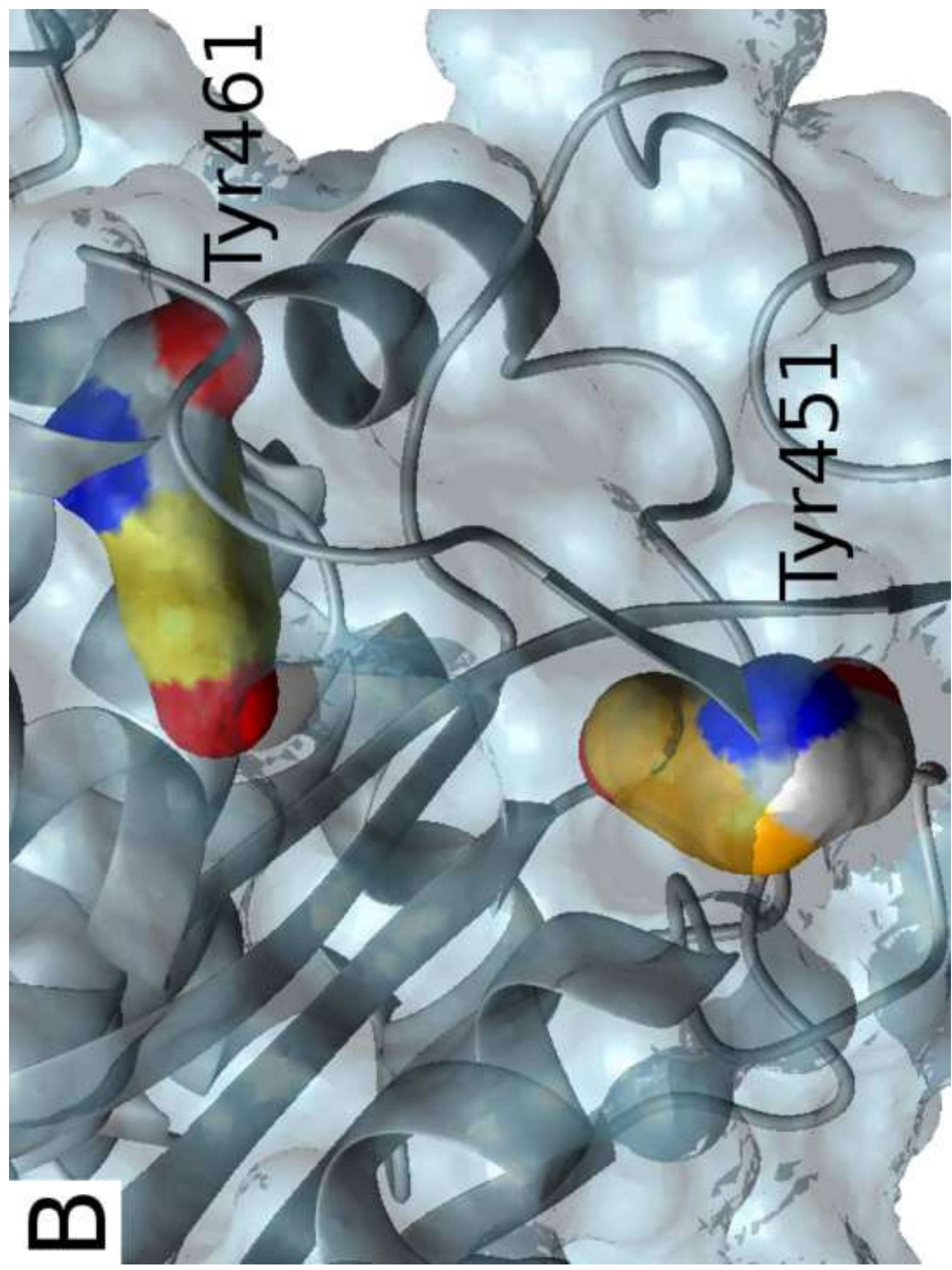




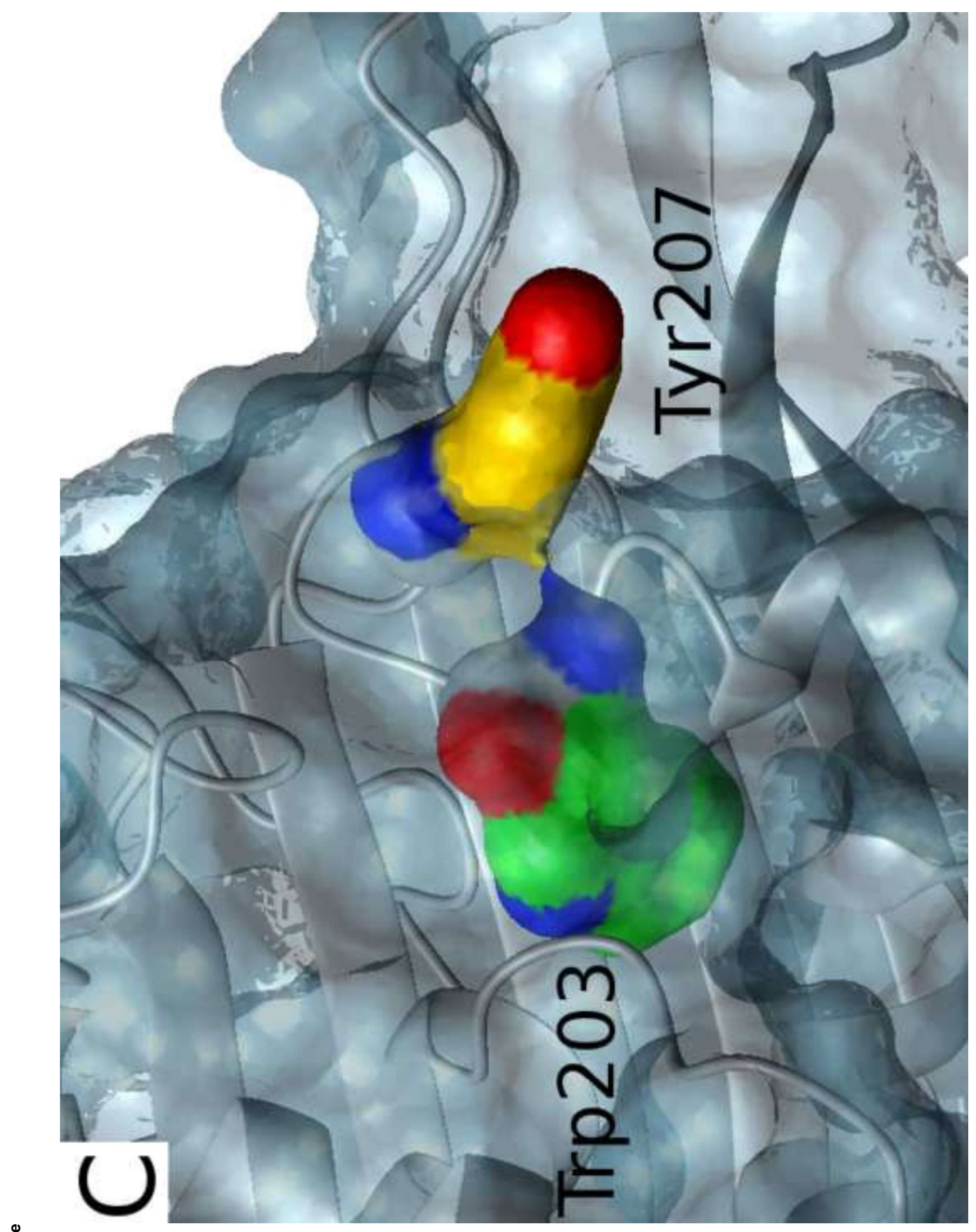


ACCEPTED MANUSCRIPT

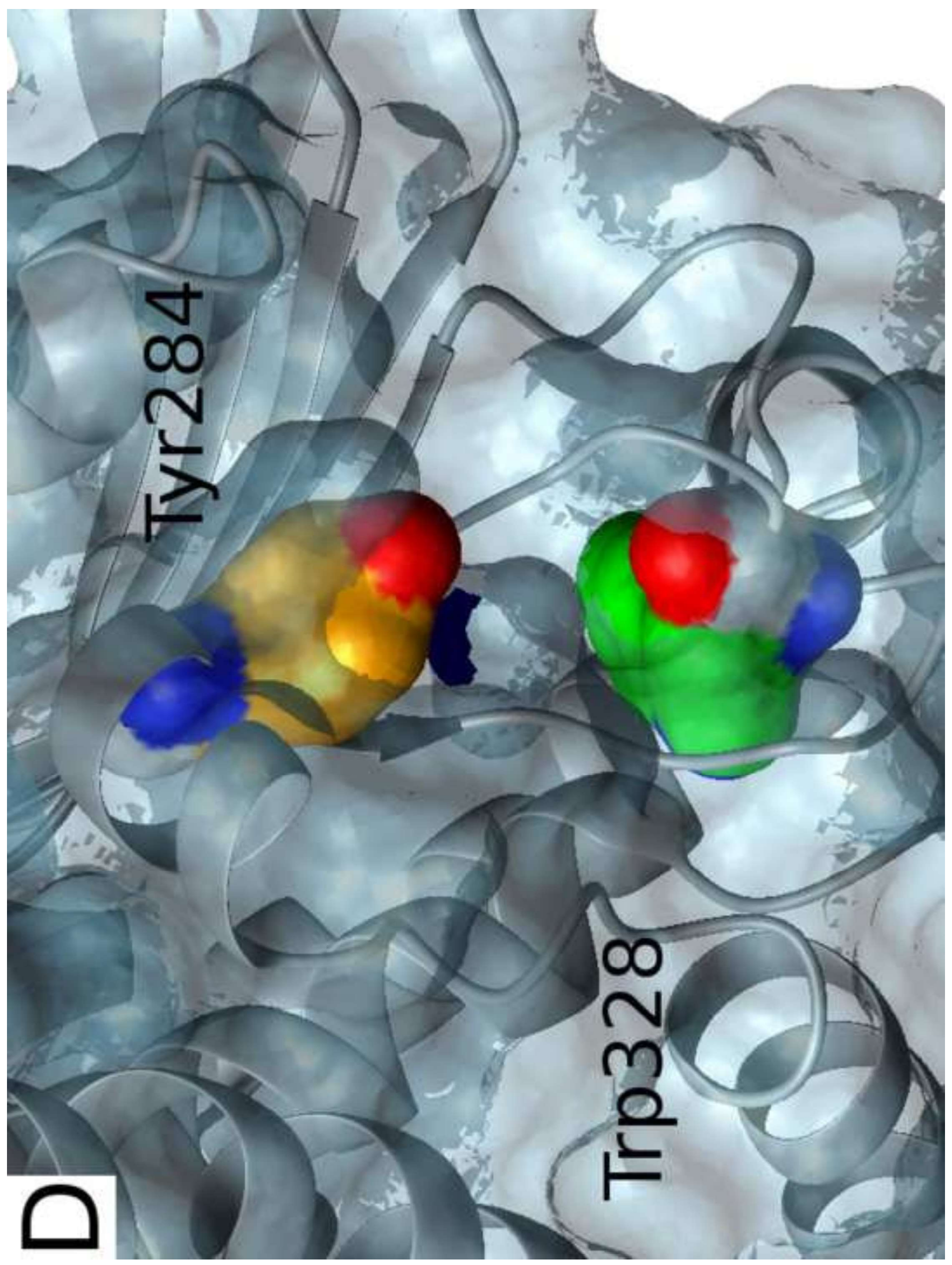

